\title{
In-situ DRIFTS and NAP-XPS Exploration of the Complexity of CO2 Hydrogenation over Size Controlled Pt Nanoparticles Supported on Mesoporous NiO
}

András Sápi, Gyula Halasi, Janos Kiss, Dorina G. Dobó, Koppány L. Juhász, Vanessza J Kolcsár, Zsuzsa Ferencz, Gabor Vari, Vladimír Matolín, András Erd\#helyi, Akos Kukovecz, and Zoltán Kónya

J. Phys. Chem. C, Just Accepted Manuscript • DOI: 10.1021/acs.jpcc.8b00061 • Publication Date (Web): 21 Feb 2018

Downloaded from http://pubs.acs.org on February 24, 2018

\section{Just Accepted}

"Just Accepted" manuscripts have been peer-reviewed and accepted for publication. They are posted online prior to technical editing, formatting for publication and author proofing. The American Chemical Society provides "Just Accepted" as a service to the research community to expedite the dissemination of scientific material as soon as possible after acceptance. "Just Accepted" manuscripts appear in full in PDF format accompanied by an HTML abstract. "Just Accepted" manuscripts have been fully peer reviewed, but should not be considered the official version of record. They are citable by the Digital Object Identifier (DOIB). "Just Accepted" is an optional service offered to authors. Therefore, the "Just Accepted" Web site may not include all articles that will be published in the journal. After a manuscript is technically edited and formatted, it will be removed from the "Just Accepted" Web site and published as an ASAP article. Note that technical editing may introduce minor changes to the manuscript text and/or graphics which could affect content, and all legal disclaimers and ethical guidelines that apply to the journal pertain. ACS cannot be held responsible for errors or consequences arising from the use of information contained in these "Just Accepted" manuscripts. 


\title{
In-situ DRIFTS and NAP-XPS Exploration of the Complexity of $\mathrm{CO}_{2}$ Hydrogenation over Size Controlled Pt Nanoparticles Supported on Mesoporous $\mathrm{NiO}$
}

András Sápi ${ }^{*}+,+$, Gyula Halasi ${ }^{\dagger,+}$, János Kiss $^{\Psi,+}$, Dorina G. Dobó ${ }^{\dagger}$, Koppány L. Juhász ${ }^{\dagger}$, Vanessza J. Kolcsár ${ }^{\dagger}$, Zsuzsa Ferencz ${ }^{\varphi}$, Gábor Vári ${ }^{\dagger}, V_{\text {Vladimír Matolin }}^{\phi}$, András Erdőhelyi $^{\varphi}$, Ákos Kukovecz ${ }^{\dagger}$, Zoltán Kónya ${ }^{\dagger, \Psi}$

${ }^{\dagger}$ Department of Applied and Environmental Chemistry, University of Szeged, H-6720 Szeged, Hungary

${ }^{\varphi}$ Department of Physical Chemistry and Material Science, University of Szeged, H-6720 Szeged, Hungary

${ }^{\phi}$ Surface Physics Group, Charles University in Prague, CZ-180 00 Praha 8 - Libeň, Czech Republic

${ }^{\Psi}$ MTA-SZTE Reaction Kinetics and Surface Chemistry Research Group, University of Szeged, H-6720 Szeged, Hungary

\begin{abstract}
Pt nanoparticles were anchored onto the surface of mesoporous nickeloxide supports $(\mathrm{NiO})$. Pt/NiO samples were compared to pristine $\mathrm{NiO}$ and $\mathrm{Pt} / \mathrm{SBA}-15$ silica catalysts in $\mathrm{CO}_{2}$ hydrogenation to form carbon-monoxide, methane and ethane at 473-673 K. $1 \% \mathrm{Pt} / \mathrm{NiO}$ were $\sim 20$ times and $\sim 1.5$ times more active at $493 \mathrm{~K}$ compared to Pt/SBA-15 and $\mathrm{NiO}$ catalysts, respectively. However, the Pt-free $\mathrm{NiO}$ support has an activity of $120 \%$ compared to $\mathrm{Pt} / \mathrm{NiO}$ catalysts at $673 \mathrm{~K}$. In the case of $1 \% \mathrm{Pt} / \mathrm{SBA}-15$ catalyst, selectivity towards methane was $13 \%$, while it was $90 \%$ and $98 \%$ for $\mathrm{NiO}$ and $1 \% \mathrm{Pt} / \mathrm{NiO}$ at $673 \mathrm{~K}$, respectively. Exploration of the results of the reactions was performed by Near Ambient Pressure X-ray Photoelectron Spectroscopy (NAP-XPS) as well as in-situ Diffuse Reflectance
\end{abstract}


Infrared Fourier Transform Spectroscopy (DRIFTS). In the case of pure NiO, we found that the surface of the support was mainly covered by elemental Ni under reaction condition, where the $\mathrm{Ni} / \mathrm{NiO}_{\mathrm{x}}$ system is responsible for the high activity of Pt-free catalyst. In the case of $\mathrm{Pt} / \mathrm{NiO}, \mathrm{Pt}$ improves the reduction of $\mathrm{NiO}_{\mathrm{x}}$ towards metallic $\mathrm{Ni}$. In the case of the $1 \% \mathrm{Pt} / \mathrm{NiO}$ catalysts, the presence of limited amount of Pt resulted in an optimal quantity of oxidized Pt fraction at $673 \mathrm{~K}$ showing the presence of a Pt/PtO $/ \mathrm{Ni} / \mathrm{NiO}_{\mathrm{x}}$ mixed phase where the different interfaces may be responsible for the high activity and selectivity towards methane. In the case of pure $\mathrm{NiO}$ under reaction condition, small amounts of formaldehyde as well as hydrogen perturbed $\mathrm{CO}\left[\mathrm{H}_{\mathrm{n}} \mathrm{CO}(\mathrm{n}=1,2)\right]$ were detected. However, in the case of $1 \% \mathrm{Pt} / \mathrm{NiO}$ catalysts, besides the absence of formaldehyde a significant amount of $\mathrm{H}_{n} \mathrm{CO}(n=2-3)$ was present on the surface responsible for the high activity and methane selectivity.

\section{INTRODUCTION}

Carbon-dioxide conversion into fuels is highly relevant today both from the process improvement and from the environmental points of view ${ }^{1,2,3}$. Heterogeneous catalysis ${ }^{4}$, electrochemistry $^{5}$, photochemistry $^{6}$ or photoelectrochemistry $^{7,8}$ etc. are used to find the perfect solution for carbon dioxide reduction towards sufficient energy forming methods.

Noble metal (Rh, Ru, Pt, Pd) or Ni, Fe, Co based catalysts are productive materials for methanation reactions ${ }^{9,10}$ and $\mathrm{CuO} / \mathrm{ZnO} / \mathrm{Al}_{2} \mathrm{O}_{3}$ systems are used for methanol synthesis ${ }^{11}$. $\mathrm{MnO}_{\mathrm{x}} / \mathrm{CoO}_{\mathrm{x}}$ hybrid catalysts are promising candidates for low pressure high energy fuel synthesis ${ }^{4}$. Pt supported on $\mathrm{Nb}_{2} \mathrm{O}_{5}$ or $\mathrm{ZrO}_{2}$ is also active in low temperature $\mathrm{CO}_{2}$ hydrogenation ${ }^{12}$. Nickel based catalysts are cost efficient and have high efficiency in $\mathrm{CO}_{2}$ methanation reactions ${ }^{9} . \mathrm{Pt} / \mathrm{NiO}$ systems are active in $\mathrm{C}=\mathrm{O}$ bond activation ${ }^{13}$, where the $\mathrm{Pt} / \mathrm{NiO}$ interface as well as the oxidation state of the support play a role in the reaction pathways. Size controlled Pt nanoparticles anchored onto the surface of designed mesoporous $\mathrm{NiO}$ films resulted in a high efficiency photoelectrochemical catalyst ${ }^{7}$.

Recent developments in engineering the metal-support interaction in $\mathrm{Co}_{3} \mathrm{O}_{4}, \mathrm{MnO}_{2}$, and $\mathrm{CeO}_{2}$ supported Pt nanoparticle systems have resulted in catalysts with enhanced activity in the $\mathrm{CO}$ oxidation reaction ${ }^{13}$. Another major achievement was the $50 \%$ reduction of the $\mathrm{CO}_{2}$ methanation activation energy by deliberately exploiting the hydrogen spillover phenomenon ${ }^{14}$. In-situ investigation methods were used successfully to facilitate the in-depth understanding of the reactions, reactants, intermediates, and the surface chemistry of the 
catalysts under reaction conditions ${ }^{15,16,17}$. Based on the knowledge accumulated about the activity, mechanism, and selectivity of the $\mathrm{CO}_{2}$ hydrogenation reaction, such advances correspond to major steps beyond trial-and-error catalyst exploration.

Despite the potential advantages of $\mathrm{Pt} / \mathrm{NiO}$ systems, studies on the rational design of $\mathrm{Pt} / \mathrm{NiO}$ catalysts are scarce and somewhat contradictory. The structure of the active catalysts as well as the mechanism of the reaction and the nature of the surface intermediates are hardly investigated under reaction conditions in $\mathrm{CO}_{2}$ hydrogenation. From earlier reports one could infer that the $\mathrm{CO}_{2}$ hydrogenation reaction over $\mathrm{Pt} / \mathrm{NiO}$ catalysts may include nickel-oxide reduction towards elemental nickel with or without $\mathrm{Pt}$ enhancement ${ }^{18}$, carbonate and formate formation on the surface of the metal or the oxide ${ }^{19,20}$, formation of $\mathrm{CO}$ and hydrogen perturbed $\mathrm{CO}$ on the metal surface which can turn into $\mathrm{CO}$ as well as low weight hydrocarbon (e.g. $\mathrm{CH}_{4}$ ) products ${ }^{21}$. The debate on these questions is a hot issue today in the field.

We report here on anchoring size controlled Pt nanoparticles with $4.8 \mathrm{~nm}$ diameter onto the surface of a designed 3D mesoporous nickel-oxide support. $\mathrm{Pt} / \mathrm{NiO}$, pristine $\mathrm{NiO}$ as well as $\mathrm{Pt}$ supported SBA-15 catalysts were tested in $\mathrm{CO}_{2}$ hydrogenation in the gas phase in a flow reactor between 493-673 K. The catalysts were monitored with Temperature Programmed Reduction (TPR) and Near Ambient Pressure X-ray Photoelectron Spectroscopy (NAP-XPS) as well as in-situ Diffuse Reflectance Infrared Fourier Transform Spectroscopy (DRIFTS) under reaction conditions. $1 \% \mathrm{Pt} / \mathrm{NiO}$ sample had the highest activity in $\mathrm{CO}_{2}$ hydrogenation at $693 \mathrm{~K}$, where the main product was $\mathrm{CH}_{4}$. Pure mesoporous nickel-oxide support showed significant activity due to the $\mathrm{Ni} / \mathrm{NiO}$ interface on the surface.

The reducibility of oxide supports in the presence of metal catalysts is crucial for deep understanding of hydrogenation reactions. The lack of knowledge on nickel-oxide supported Pt systems also conducted our attention to investigate mesoporous nickel oxide supported Pt nanoparticles with in-situ techniques under parameters of hydrogenation of $\mathrm{CO}_{2}$.

We found that under reaction conditions, in the case of $\mathrm{Pt} / \mathrm{NiO}$ catalyst, there is a complex interface of $\mathrm{Ni} / \mathrm{NiO}_{\mathrm{x}} / \mathrm{PtO} / \mathrm{Pt}$ where $\mathrm{Pt}$ boosts the reduction of $\mathrm{NiO}$ to metallic $\mathrm{Ni}$ on the top layers via the assistance of oxygen migration to the surface from the bulk. Furthermore, in the case of the most active $1 \% \mathrm{Pt} / \mathrm{NiO}$ catalyst, the surface was highly covered by hydrogen perturbated $\mathrm{CO}$ under reaction condition showing the important role of such intermediates towards the high $\mathrm{CH}_{4}$ activity and selectivity. Interestingly, in the case of the pristine $\mathrm{NiO}$ and 
the high Pt content $\mathrm{Pt} / \mathrm{NiO}$ catalyst, formaldehyde was found on the surface, which was stable and may decompose towards $\mathrm{CO}$ and carbonate.

\section{EXPERIMENTAL SECTION}

\section{Synthesis of $4.8 \mathrm{~nm} \mathrm{Pt}$ nanoparticles}

Synthesis of $4.8 \mathrm{~nm}$ particles is based on a modified version of the polyol-method ${ }^{22,7}$. Briefly, $0.04 \mathrm{~g} \mathrm{Pt}\left(\mathrm{C}_{5} \mathrm{H}_{7} \mathrm{O}_{2}\right)_{2}$ and $0.035 \mathrm{~g}$ polyvinylpyrrolidone (PVP, $\mathrm{MW}=40,000$ ) are solved in $5 \mathrm{ml}$ ethylene-glycol and ultrasonicated for 30 minutes to obtain a homogenous solution. The reactor is a three-necked round bottom flask, which is evacuated and purged with atmospheric pressure argon gas for several cycles to get rid of additional oxygen and water. After three purging cycles, the flask was immersed in an oil bath heated to $200{ }^{\circ} \mathrm{C}$ under vigorous stirring of the reaction mixture as well as the oil bath. After 10 minutes of reaction, the flask was cooled down to room temperature. The suspension is precipitated by adding acetone and centrifuging. The nanoparticles are washed by centrifuging with hexane and redispersing in ethanol for at least 2-3 cycles, and finally redispersed in ethanol.

\section{$\underline{\text { Synthesis of Mesoporous Nickel Oxide support }}$}

For the preparation of mesoporous nickel-oxide support $(\mathrm{NiO})$, hard template replica method was applied $^{13}$. For the synthesis, KIT-6 silica was used as a hard template. For the synthesis of KIT-6, $27 \mathrm{~g}$ of Pluronic-123 block copolymer and $43.5 \mathrm{ml} \mathrm{HCl}$ was dissolved in $980 \mathrm{ml}$ water. After $30 \mathrm{~min}, 33.3 \mathrm{ml} \mathrm{n}$-butanol was added to the solution at $35^{\circ} \mathrm{C}$ under vigorous stirring. After $1 \mathrm{~h}$ of stirring, $58 \mathrm{~g}$ of Tetraethyl orthosilicate (TEOS) was added dropwise to the solution followed by stirring for $24 \mathrm{~h}$ at $35^{\circ} \mathrm{C}$. The solution is stored in a capped plastic autoclave at $40{ }^{\circ} \mathrm{C}$ for another $24 \mathrm{~h}$. Then the solid product was filtered, dried at $90{ }^{\circ} \mathrm{C}$ overnight and calcined at $550{ }^{\circ} \mathrm{C}$ for $6 \mathrm{~h}$.

$\mathrm{NiO}$ was prepared through the hard template method using the as-prepared KIT-6. In a typical synthesis, $4,65 \mathrm{~g} \mathrm{Ni}\left(\mathrm{NO}_{3}\right)_{2} \cdot 6 \mathrm{H}_{2} \mathrm{O}$ was dissolved in $8 \mathrm{ml}$ water at $65^{\circ} \mathrm{C}$ and in another flask 4 g KIT-6 was dissolved in $40 \mathrm{ml}$ toluene at $65^{\circ} \mathrm{C}$. They were stirring separetly for $30 \mathrm{~min}$, then the second suspension was transferred into the first with $10 \mathrm{ml}$ of toluene. Vigorous stirring was applied to the mixture at $65^{\circ} \mathrm{C}$ until the total evaporation of toluene. After the evaporation, the precipitated product was collected and dried at $60^{\circ} \mathrm{C}$ overnight, followed by calcination at $300{ }^{\circ} \mathrm{C}$ for $6 \mathrm{~h}$. The silica template was completely removed by several washing 
steps using $200 \mathrm{ml}, 2 \mathrm{M}$ aqueous $\mathrm{NaOH}$ solution and destilled $\mathrm{H}_{2} \mathrm{O}$. The sample was washed to neutral $\mathrm{pH}$. The filtered product was dried at $50^{\circ} \mathrm{C}$ overnight.

\section{Synthesis of SBA-15 mesoporous silica support}

SBA-15 mesoporous silica support was synthesized from tetraethyl orthosilicate (TEOS) by a soft template method. Here, $8 \mathrm{~g}$ of pre-melted Pluronic-123, $60 \mathrm{ml}$ distilled water and $240 \mathrm{ml}$ of $2 \mathrm{M} \mathrm{HCl}$ solution were mixed at $40{ }^{\circ} \mathrm{C}$ for 2 hours. After the dissolution of P-123, $17 \mathrm{~g}$ of TEOS was added dropwise to the mixture at $40^{\circ} \mathrm{C}$ and continuous stirring was applied for 20 hours. Stirring was continued for 36 hours at $60^{\circ} \mathrm{C}$. After the synthesis, the product was filtered and washed with distilled water. Then, the product was heated to $100{ }^{\circ} \mathrm{C}$ with a heating rate of $2{ }^{\circ} \mathrm{C} \cdot \mathrm{min}^{-1}$ and aged for 5 hours; then the temperature was elevated to $550{ }^{\circ} \mathrm{C}$ with a heating rate of $1{ }^{\circ} \mathrm{C} \cdot \mathrm{min}^{-1}$. After 4 hours of calcination, the product was ready for further use.

\section{Synthesis of Mesoporous NiO and SBA-15 supported Pt catalysts}

To fabricate supported catalysts, the ethanol suspension of Pt nanoparticles and the different supports (NiO, SBA-15) were mixed in ethanol and sonicated in an ultrasonic bath $(40 \mathrm{kHz}$, $80 \mathrm{~W}$ ) for $3 \mathrm{hrs}$. The supported nanoparticles were collected by centrifugation. The products were washed with ethanol three times before they were dried at $80{ }^{\circ} \mathrm{C}$ overnight.

\section{Hydrogenation of carbon-dioxide in a continuous flow reactor}

Before the catalytic experiments either in a continuous-flow reactor or in the ambient pressure XPS chamber the as received catalysts were oxidized in $\mathrm{O}_{2}$ atmosphere at $573 \mathrm{~K}$ for 30 min to remove the surface contaminants as well as the PVP capping agent ${ }^{23,24}$ and thereafter were reduced in $\mathrm{H}_{2}$ at $573 \mathrm{~K}$ for $60 \mathrm{~min}$.

Catalytic reactions were carried out in a fixed-bed continuous-flow reactor $(200 \mathrm{~mm}$ long with $8 \mathrm{~mm}$ i.d.), which was heated externally. The dead volume of the reactor was filled with quartz beads. The operating temperature was controlled by a thermocouple placed inside the oven close to the reactor wall, to assure precise temperature measurement. For catalytic studies small fragments (about $1 \mathrm{~mm}$ ) of slightly compressed pellets were used. Typically, the reactor filling contained $20-150 \mathrm{mg}$ of catalyst. In the reacting gas mixture, the $\mathrm{CO}_{2}: \mathrm{H}_{2}$ molar 
ratio was 1:4, if not denoted otherwise. The $\mathrm{CO}_{2}: \mathrm{H}_{2}$ mixture was fed with the help of mass flow controllers (Aalborg), the total flow rate was $50 \mathrm{ml} / \mathrm{min}$. The reacting gas mixture flow entered and left the reactor through an externally heated tube to avoid condensation. The analysis of the products and reactants was performed with an Agilent $6890 \mathrm{~N}$ gas chromatograph using HP-PLOTQ column. The gases were detected simultaneously by thermal conductivity (TCD) and flame ionization (FID) detectors. The $\mathrm{CO}_{2}$ was transformed by a methanizer to methane, and it was also analyzed by FID.

In a typical measurement, after the pretreatment process, the samples were cooled in flowing $\mathrm{H}_{2}$ to $473 \mathrm{~K}$ and the catalysts were introduced to $\mathrm{CO}_{2}: \mathrm{H}_{2}$ mixture with a molar ratio of $1: 4$ with a total flow rate of $50 \mathrm{ml} / \mathrm{min}$ at $473 \mathrm{~K}$ and the reactor was heated linearly at a rate of 5 $\mathrm{K} / \mathrm{min}$ up to $673 \mathrm{~K}$ and equilibrated for $120 \mathrm{~min}$. After this method, we started measurements in the case of $1 \% \mathrm{Pt} / \mathrm{SBA}-15$ and $5 \% \mathrm{Pt} / \mathrm{SBA}-15$ at $673 \mathrm{~K}, 643 \mathrm{~K}, 623 \mathrm{~K}, 593 \mathrm{~K}$ and then were heated back to $613 \mathrm{~K}, 653 \mathrm{~K}, 673 \mathrm{~K}$ after waiting for constant activity at each temperature $(\sim 1 \mathrm{hr})$. In the case of $\mathrm{NiO}, 1 \% \mathrm{Pt} / \mathrm{NiO}$ and $5 \% \mathrm{Pt} / \mathrm{NiO}$ catalysts, we used temperatures of $673 \mathrm{~K}, 583 \mathrm{~K}, 568 \mathrm{~K}, 553 \mathrm{~K}, 538 \mathrm{~K}$ and $523 \mathrm{~K}$. We plotted corresponding Arrhenius-plots in the conversion regime of $0.5-10 \%$.

\section{$\underline{\text { Temperature Programmed Reduction (TPR) }}$}

The temperature-programmed reduction (TPR) was carried out in a BELCAT-A apparatus using a reactor (quartz tube with $9 \mathrm{~mm}$ outer diameter) that was externally heated. Before the measurements, the catalyst samples were treated in oxygen at $573 \mathrm{~K}$ for $30 \mathrm{~min}$. Thereafter, the sample was cooled in flowing Ar to room temperature and equilibrated for $15 \mathrm{~min}$. The oxidized sample was flushed with Ar containing $10 \% \mathrm{H}_{2}$, the reactor was heated linearly at a rate of $20 \mathrm{~K} \cdot \mathrm{min}^{-1}$ up to $1373 \mathrm{~K}$ and the $\mathrm{H}_{2}$ consumption was detected by a thermal conductivity detector (TCD).

Furthermore, after the catalytic experiments, TPR measurements were performed on the spent catalysts to gain information on the quality and quantity of deposited carbon. After running the reactions of $\mathrm{CO}_{2}: \mathrm{H}_{2}$ mixtures at $673 \mathrm{~K}$ for $120 \mathrm{~min}$, the reactor was flushed with $\mathrm{He}$ at the reaction temperature. The sample was subsequently cooled to ambient temperature, the helium flow was changed to $\mathrm{H}_{2}$, and the sample was heated up to $1173 \mathrm{~K}$ with a $20 \mathrm{~K} \cdot \mathrm{min}^{-1}$ heating rate. The in situ formed products were analyzed and quantified by gas chromatography. 


\section{Near Ambient Pressure X-ray Photoelectron Spectoscropy (NAP-XPS)}

An ultra-high vacuum system equipped with a hemispherical analyzer (PHOIBOS series with 1 DLD detector) and a monochromatic $\mathrm{AlK}_{\alpha}(\mathrm{h} v=1486.6 \mathrm{eV}) \mathrm{X}$-ray radiation source was employed to perform the X-ray photoelectron spectroscopy ${ }^{25}$. The binding energy scale of all XPS spectra was calibrated according to the $\mathrm{C} 1 \mathrm{~s}$ reference $(284.3 \mathrm{eV}$, which corresponds to the adventitious carbon). However, only the relative energy position of XPS photoelectron lines in each sample is needed to determine the valence band offset (VBO) and the absolute energy calibration for a sample does not affect the ultimate result. The XPS spectra were analysed by fitting the Shirley-type function, which is commonly used in XP spectra deconvolution ${ }^{26}$ and a sum of Voigt functions to the experimental results, using the KolXPD software $^{24}$. The catalysts were pre-treated (oxidized and reduced) before the experiments the same way as before the catalytic measurements. The partial pressure of the oxygen under the oxidation was 20 mbar and in the case of reduction the hydrogen was set to 5 mbar. Under reaction conditions, the ratio of the $\mathrm{CO}_{2}: \mathrm{H}_{2}$ was set to $1: 4$ with a total pressure of 5 mbar.

\section{$\underline{\text { In-situ Diffuse Reflectance Infrared Fourier Transform Spectroscopy (DRIFTS) }}$}

\section{Infrared spectroscopy measurements were carried out with an 'Agilent Cary-670' FTIR} spectrometer equipped with 'Harrick Praying Mantis' diffuse reflectance attachment. The sample holder had two $\mathrm{BaF}_{2}$ windows in the infrared path. The spectrometer was purged with dry nitrogen. The spectrum of the pretreated catalyst was used as background. At room temperature, a $\mathrm{CO}_{2}-$ to- $\mathrm{H}_{2}$ molar ratio of 1:4 was introduced into the DRIFTS cell. The tubes were externally heated to avoid condensation. The catalyst was heated under the reaction feed linearly from room temperature to $773 \mathrm{~K}$, with a heating rate of $20 \mathrm{~K} \cdot \mathrm{min}^{-1}$ and IR spectra were measured at $50 \mathrm{~K}$ intervals. All spectra were recorded between 4000 and $900 \mathrm{~cm}^{-1}$ at a resolution of $2 \mathrm{~cm}^{-1}$. Typically, 32 scans were registered. Due to the short optical path within the DRIFTS cell, the contribution of the reactant gases was negligibly small, and from gas phase products only the most intense features were observable.

\section{$\underline{\text { High Resolution Transmission Electron Microscopy (HR-TEM) }}$}

Imaging of the different silica supports, Pt nanoparticles and derived catalysts, as well as the size distribution of the nanoparticles before and after the catalytic reaction, was performed by an FEI TECNAI G2 20 X-Twin high-resolution transmission electron microscope (equipped 
with electron diffraction) operating at an accelerating voltage of $200 \mathrm{kV}$. The samples were drop-cast onto carbon film coated copper grids from ethanol suspension.

\section{Powder X-ray Diffraction (XRD)}

XRD studies of the silica supports were performed on a Rigaku MiniFlex II instrument with a Ni-filtered $\mathrm{CuK}_{\alpha}$ source in the range of $2 \theta=10-80^{\circ}$.

\section{$\underline{\text { Gas Sorption Measurements }}$}

The specific surface area (BET method), the pore size distribution and the total pore volume were determined by the BJH method using a Quantachrome NOVA 2200 gas sorption analyzer by $\mathrm{N}_{2}$ gas adsorption/desorption at $-196^{\circ} \mathrm{C}$. Before the measurements, the samples were pre-treated in vacuum $(<\sim 0.1$ mbar $)$ at $473 \mathrm{~K}$ for 2 hours.

\section{RESULTS AND DISCUSSION}

\subsection{Characterization of the catalysts}

Platinum nanoparticles were synthesized by a polyol method from platinum-chloride precursor using ethylene glycol as a media and PVP as a capping agent ${ }^{7}$. The as-prepared Pt nanoparticles have a narrow size distribution with an average diameter of $4.8 \pm 1.5 \mathrm{~nm}$ (Fig. 1/A.). Electron Diffraction patterns confirm the presence of Pt (111), Pt (200), Pt (220) and Pt (311) crystallite planes characteristic for metallic face-centered cubic (fcc) platinum. Mesoporous nickel oxide was prepared by the replica method using KIT-6 mesoporous silica as a hard template and SBA-15 silica for reference state support were synthetized by the soft method using tetraethyl orthosilicate (TEOS) as a template ${ }^{13}$. TEM investigations confirm the mesoporous structure of the as-prepared mesoporous $\mathrm{NiO}$ and SBA-15 supports with a pore diameter of 3-6 nm (Fig. 1/B., Fig. 1/C.).

$4.8 \mathrm{~nm}$ Pt nanoparticles were successfully loaded onto the surface of the catalyst supports in both $1 \mathrm{wt} \%$ (Fig. 1/C., Fig. 1/D.) as well as in $5 \mathrm{wt} \%$ (Fig. 1/E., Fig. 1/F.) concentration. In case of $1 \%$ loading, there is a smooth distribution of the Pt nanoparticles. In the case of $5 \%$ loading, clusters of 3-7 pieces of Pt nanoparticles were also observed. 

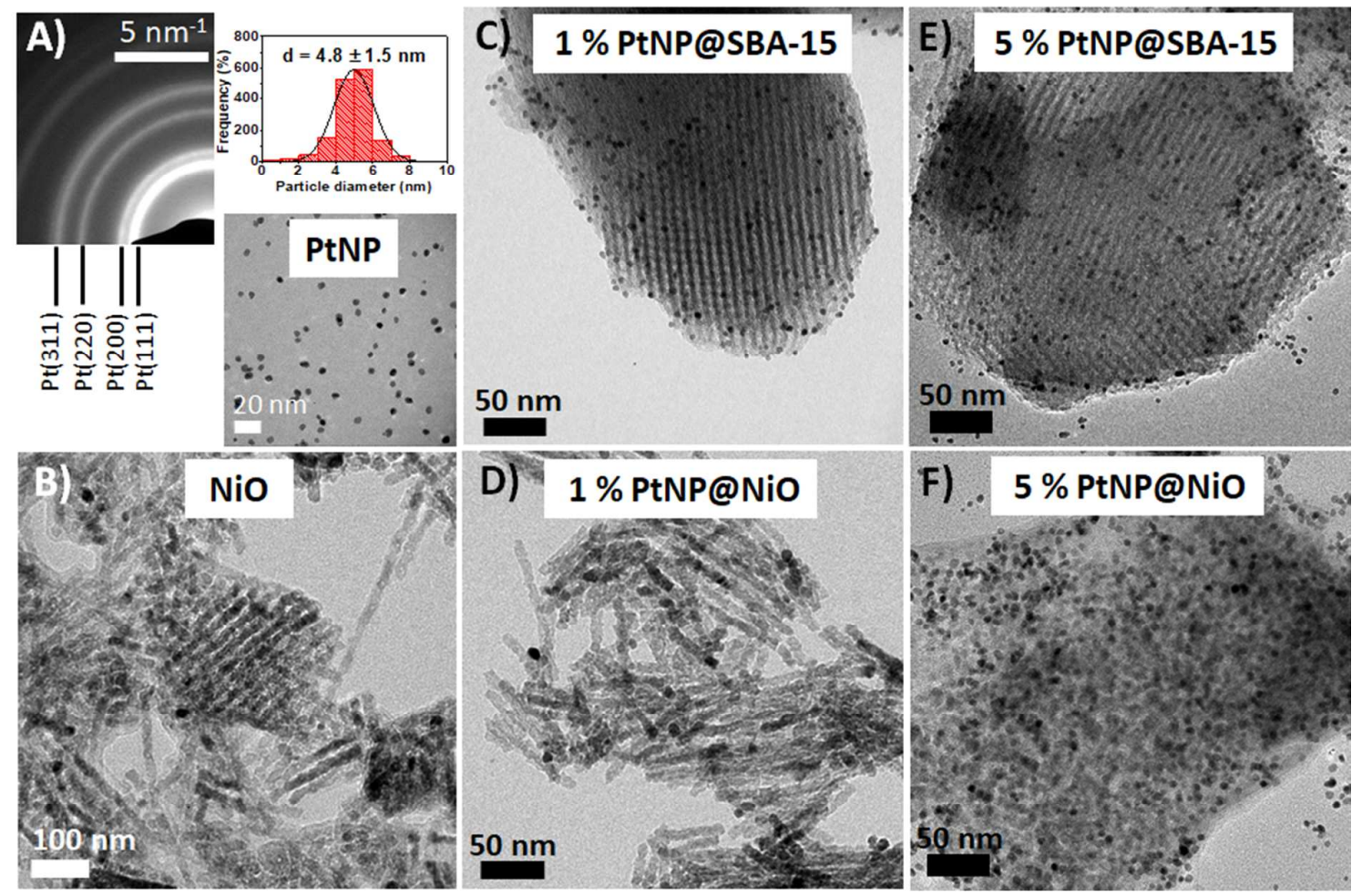

Figure 1. Typical TEM images of $4.8 \pm 1.5 \mathrm{~nm}$ metallic Pt nanoparticles with narrow size distribution (ED pattern shows the presence of metallic $\mathrm{Pt}$ ) (A), mesoporous nickel-oxide support (B), and $4.8 \mathrm{~nm}$ PtNPs supported on SBA-15 and NiO with a loading of $1 \mathrm{wt} \%$ (C, D) as well as of $5 \mathrm{wt} \%(\mathrm{E}, \mathrm{F})$

The $\mathrm{N}_{2}$ adsorption/desorption isotherms for pure $\mathrm{NiO}$ as well as for SBA-15 silica supports show a type $\mathrm{V}$ isotherm characteristic for mesoporous materials (Fig. S1/A., Fig. S1/B.). The type $\mathrm{H} 1$ hysteresis loop further strengthening the presence of an ordered structure. The specific surface area was found to be as high as $127 \mathrm{~m}^{2} / \mathrm{g}$ and $820 \mathrm{~m}^{2} / \mathrm{g}$ for pure $\mathrm{NiO}$ and SBA-15, respectively. The XRD patterns of the as-prepared NiO confirms the presence of Ni(II)O (100), (200), (220), (311) and (222) crystal planes, characteristic to the face centered cubic (fcc) nickel(II)- oxide structure (Fig. S1/C.). The broadened diffractions with lower intensity show the amorphous nature of the $\mathrm{NiO}$, which further correlates with the TEM images. In the case of the SBA-15 support, only the weak, broadened diffraction of $\mathrm{SiO}_{2}$ (101) was observed indicating the low crystallinity of the silica material (Fig. S1/D.) 


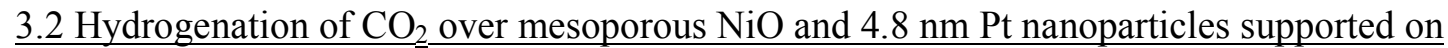

\section{$\underline{\mathrm{SBA}-15 \text { and } \mathrm{NiO}}$}

$1 \%$ and $5 \% 4.8 \mathrm{~nm}$ Pt nanoparticles supported on mesoporous nickel oxide as well as pure $\mathrm{NiO}$ and $4.8 \mathrm{~nm}$ Pt nanoparticle/SBA-15 samples for reference state were tested in $\mathrm{CO}_{2}$ hydrogenation to form carbon-monoxide, methane, and ethane at 593-673 K in a fix bed flow catalytic reactor. The summarized catalytic results are collected on Fig. 2.

$1 \% \mathrm{Pt} / \mathrm{NiO}$ was $\sim 45$ times and $\sim 1.5$ times more active at $593 \mathrm{~K}$ compared to Pt/SBA-15 and 5 $\% \mathrm{Pt} / \mathrm{NiO}$ catalysts, respectively (Fig. 2/A.). However, the Pt-free $\mathrm{NiO}$ support has an activity of $\sim 120 \%$ compared to $1 \% \mathrm{Pt} / \mathrm{NiO}$ catalysts at both $593 \mathrm{~K}$ and $673 \mathrm{~K}$ (Fig. 2/B.). In the case of $1 \% \mathrm{Pt} / \mathrm{SBA}-15$ catalyst, selectivity towards methane was $13 \%$, while it was $90 \%$ and $98 \%$ for $\mathrm{NiO}$ and 1\% Pt/NiO at $673 \mathrm{~K}$, respectively (Fig. 2/C., Fig. 2/D.).

In the case of $\mathrm{Pt} / \mathrm{SiO}_{2}$ catalysts, the main product was $\mathrm{CO}$ via the water-gas-shift reaction from $\mathrm{CO}_{2}$ which was formed at the interface of the $\mathrm{Pt}$ and $\mathrm{SiO}_{2}{ }^{27}$. In the case of pure $\mathrm{NiO}$, the high selectivity towards $\mathrm{CH}_{4}$ indicates the formation of metallic nickel on the NiO surface under reaction condition as metallic nickel is a well-known catalyst in $\mathrm{CO}_{2}$ methanation ${ }^{9,28}$. $\mathrm{Pt}$ has no significant conversion enhancing effect on the reactivity of mesoporous nickel-oxide. In the case of the most active $1 \% \mathrm{Pt} / \mathrm{NiO}$ catalyst, $78 \%$ conversion was reached at $673 \mathrm{~K}$. Size controlled Pt nanoparticles have an activity increasing effect in $1 \%$ loading. However, the activity of $5 \% \mathrm{Pt} / \mathrm{NiO}$ is lower than that of pure $\mathrm{NiO}$ catalysts. Also, the excess amount of $\mathrm{Pt}$ resulted in enhanced $\mathrm{CO}$ production showing the presence of individually working Pt surfaces blocking some of the active $\mathrm{NiO}$ sites and $\mathrm{Pt} / \mathrm{Ni} / \mathrm{NiO}_{\mathrm{x}}$ interphases.

A small amount of ethane was detected in the case of nickel-oxide support. 5\% $\mathrm{Pt} / \mathrm{NiO}$ catalysts produced 3 times more ethane $(0.12 \%)$ compared to pure $\mathrm{NiO}(0.04 \%)$ and $1 \%$ $\mathrm{Pt} / \mathrm{NiO}$ catalyst (0.03\%) (Fig. S2/A.). The catalysts remained stable at $673 \mathrm{~K}$ under the reaction condition for at least 2.5 hours (Fig. S2/B.). 

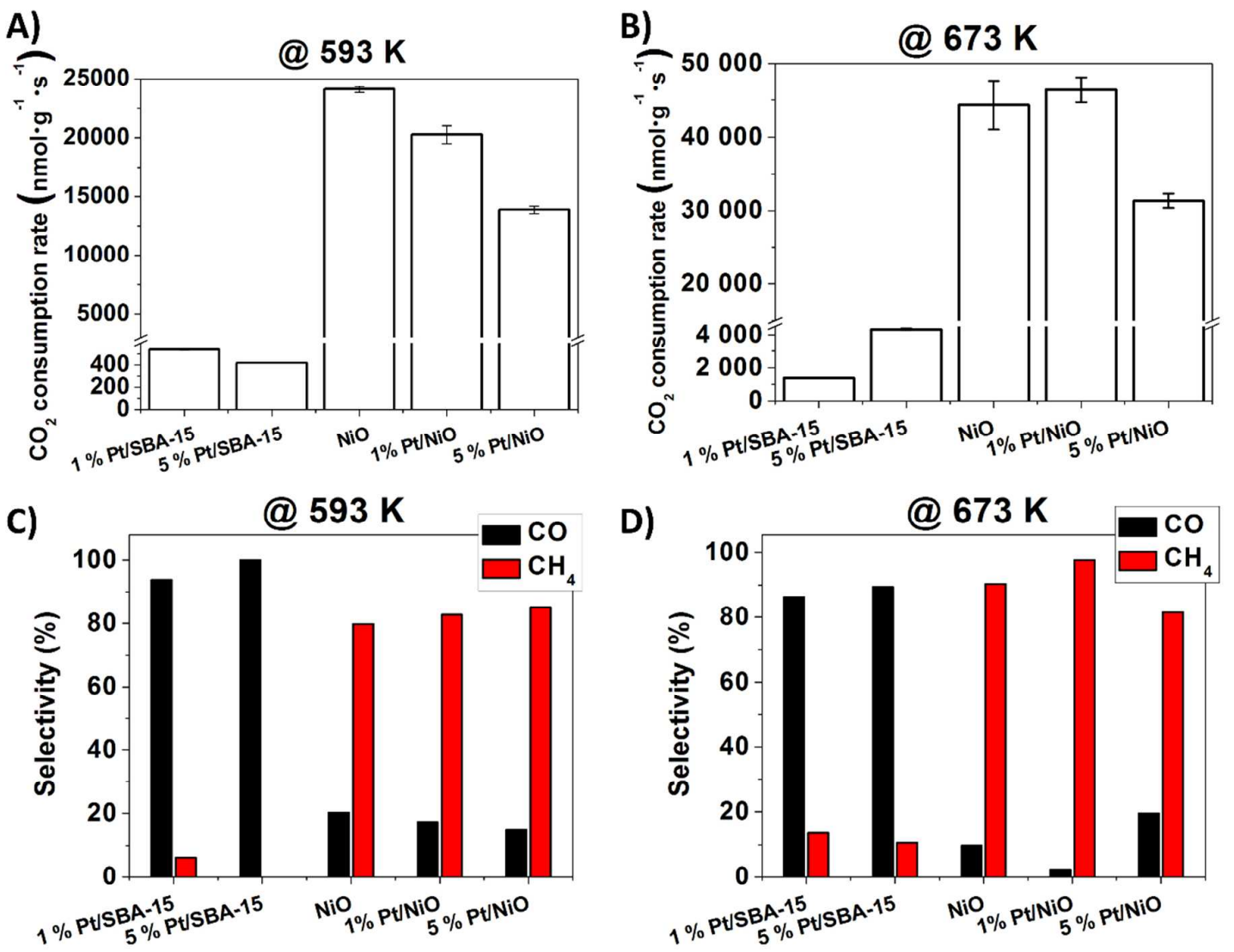

Figure 2. $\mathrm{CO}_{2}$ hydrogenation over $1 \%$ and $5 \% \mathrm{Pt} / \mathrm{NiO}, \mathrm{Pt} / \mathrm{SBA}-15$ and pure $\mathrm{NiO}$ catalysts at $593 \mathrm{~K}$ and $673 \mathrm{~K}$

Activation energy calculation was determined for all catalysts in the kinetical regime (0.5$10 \%$ conversion) at 523-623 K (Fig. S3.). For $1 \% \mathrm{Pt} / \mathrm{SBA}-15$ and $5 \% \mathrm{Pt} / \mathrm{SBA}-15$, the activation energies were $16.7 \mathrm{kcal} / \mathrm{mol}$ and $19.4 \mathrm{kcal} / \mathrm{mol}$, respectively. This results are correlated with other studies ${ }^{10}$.

In the case of Pt free mesoporous nickel oxide support, the higher activation energy (25.2 $\mathrm{kcal} / \mathrm{mol}$ ) show the presence of different mechanism. This phenomenon shows different pathway of the reaction as it is clearly seen from the fact that the selectivity towards $\mathrm{CH}_{4}$ is higher compared to the Pt/SBA-15 systems. These activation energy values for $\mathrm{CO}$ as well as for $\mathrm{CH}_{4}$ formation is comparable for the results from literature ${ }^{29}$.

In the case of mesoporous nickel oxide supported catalyst, the presence of the Pt nanoparticles resulted in a slight decrease of the activation energies. For $1 \% \mathrm{Pt} / \mathrm{NiO}$ and $5 \% \mathrm{Pt} / \mathrm{NiO}$, the 
activation energies were $22.8 \mathrm{kcal} / \mathrm{mol}$ and $20.7 \mathrm{kcal} / \mathrm{mol}$, respectively. Pt plays an important role in the reduction of nickel oxide as well as preferring other reaction routes. For deeper understanding of $\mathrm{Pt} / \mathrm{NiO}$ system in this reaction, $\mathrm{H}_{2}$ TPR, NAP-XPS as well as DRIFTS studies were performed.

\section{$\underline{3.3 \text { Temperature programmed reduction }}$}

The reduction profile of supported metal catalysts depends on the interaction of the metal with its support ${ }^{30}$. In present cases the catalysts were oxidized at $573 \mathrm{~K}$ for $30 \mathrm{~min}$. In the case of $\mathrm{Pt} / \mathrm{SBA}-15$, there is no significant interaction between Pt and support. The platinum oxide formed during oxidation treatment can be reduced at $500-850 \mathrm{~K}$. The lower TPR peak is at $580 \mathrm{~K}$, the higher is at $697 \mathrm{~K}$ (Fig. S4.). $\mathrm{Pt}^{0}$ can be obtained in this temperature range on SBA-15 and $\mathrm{SiO}_{2}$ according to the literature ${ }^{31,32}$. Where the interaction of Pt with oxide support is strong as in $\mathrm{Pt} / \mathrm{NiO}$ case ${ }^{33}$, the positively charged platinum $\left(\mathrm{Pt}^{2+}\right.$ or $\left.\mathrm{Pt}^{4+}\right)$ is relatively unstable and is easily reduced to $\mathrm{Pt}^{0}$.

In the case of the Pt anchored onto mesoporous nickel oxide support, part of the platinum is reduced at $488 \mathrm{~K}$. However, the reduction of the other part of the platinum take places at higher temperatures (at the low temperature tailing of the feature of $\mathrm{NiO}$ ) (Fig. 3.).

The reducibility of $\mathrm{NiO}$ as catalyst and as catalyst support depends on the morphology, porosity and the preparation methods. In harmony with the literature ${ }^{34}$, the $\mathrm{NiO}$ can be reduced in two steps (Fig. 3.); the peak at $673 \mathrm{~K}$ could be attributed to reduction from $\mathrm{Ni}^{2+}$ to $\mathrm{Ni}^{\delta+}$ and the peak at $788 \mathrm{~K}$ is the characteristic temperature of the $\mathrm{Ni}^{8+}$ to $\mathrm{Ni}^{0}$ reduction. $\mathrm{A}$ very small TPR peak at $522 \mathrm{~K}$ is probably due to the reduction of a trace amount of $\mathrm{Ni}^{3+}$.

The reducibility of $\mathrm{NiO}$ dramatically changes in the presence of Pt. Both characteristic TPR peaks moved to lower temperature. These changes are increasing with Pt metal content even at same sizes $(4.8 \mathrm{~nm})$. In the case of the $1 \% \mathrm{Pt} / \mathrm{NiO}$, the TPR peaks are at 668 and $731 \mathrm{~K}$. At $5 \%$ metal content, the peak temperatures moved further to 664 and $713 \mathrm{~K}$ (Fig. 3.). In the case of $5 \% \mathrm{Pt}$ content, the $\mathrm{H}_{2}$ consumption of second peak is less than that of first step, suggesting that $\mathrm{NiO}$ can be reduced to a great degree during the first step. It should be emphasized that TPR is a dynamic method therefore, if the reduction was carried out under isothermic condition, the same reduction trend would be achieved at lower temperatures. 


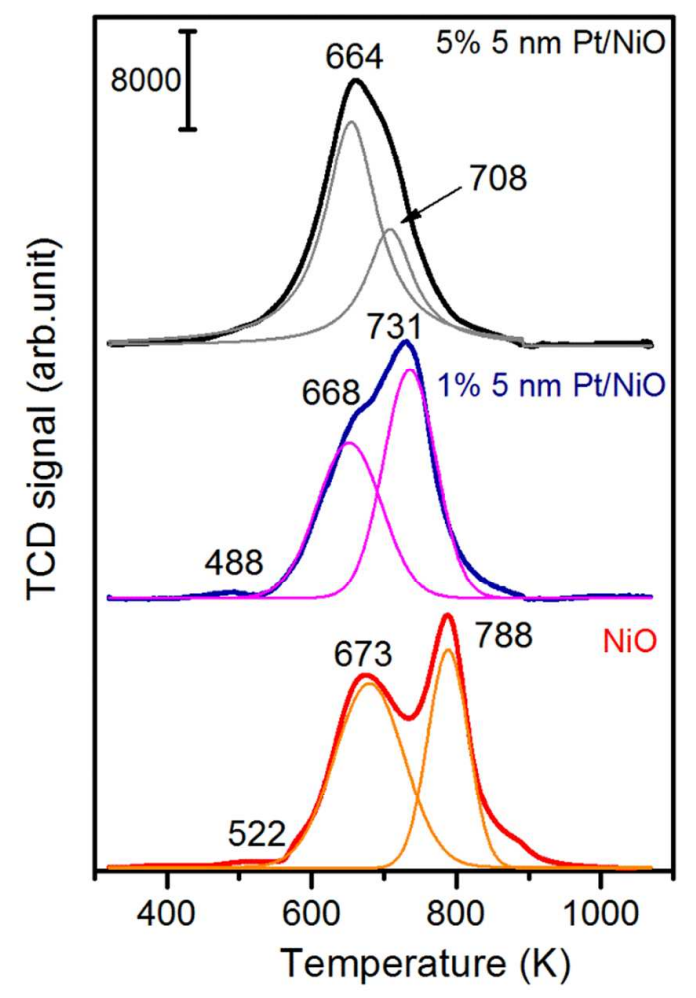

Figure 3. TPR profile for $\mathrm{NiO}$ and $\mathrm{NiO}$ supported $4.8 \mathrm{~nm}$ Pt nanoparticles with a loading of 1 $\%$ as well as $5 \%$ showing the enhancing effect of $\mathrm{Pt}$ on $\mathrm{NiO}$ reduction towards metallic nickel.

\subsection{NAP-X-ray photoelectron spectroscopy during the catalytic reaction}

Pure nickel oxide, $5 \% \mathrm{Pt} / \mathrm{NiO}$ catalyst was tested in NAP-XPS measurements under reaction conditions $\left(573 \mathrm{~K}-673 \mathrm{~K}, \mathrm{p}=5 \mathrm{mbar}, \mathrm{CO}_{2}: \mathrm{H}_{2}\right.$ ratio was $\left.1: 4\right)$. Before catalytic reactions the

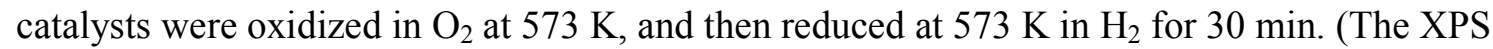
spectra recorded during different treatments are presented in the Supporting Information). In the case of the as-prepared and oxidized $\mathrm{NiO}$, the $\mathrm{Ni} 2 \mathrm{p}$ shows two different $\mathrm{Ni}$ states: one corresponds to $\mathrm{NiO}(853.4 \mathrm{eV})$ the other is very close to $\mathrm{Ni}(\mathrm{OH})_{2}$ form $(855.6 \mathrm{eV})$ (Fig. S5/A.). A strong satellite appeared at $860.6 \mathrm{eV}$, which is characteristic for $\mathrm{NiO}$. After oxidation a typical $\mathrm{Ni} 2 \mathrm{p}_{3 / 2}$ structure appeared at 853.1 and $855.1 \mathrm{eV}$ and an intense satellite was detected at $860.4 .0 \mathrm{eV}$. Very similar spectrum was reported previously for polycrystalline and macro-mesoporous $\mathrm{NiO}^{35,36,33}$. After reduction at $573 \mathrm{~K}$, the main peak moved to 852.4 
$\mathrm{eV}$, and a peak developed at $858.1 \mathrm{eV}$ as a satellite indicated that metallic $\mathrm{Ni}$ is dominant ${ }^{37}$, a small but remarkable oxidized fraction remained at $853.2 \mathrm{eV}$.

The $\mathrm{C} 1 \mathrm{~s}$ signals are shown in Fig. S5/B. The as prepared sample contains $\mathrm{C}$ 1s features ( 284.3 and around $288.2 \mathrm{eV}$ ) due to the adventitious carbon and precursor molecules. After oxidation-reduction, only a small intensity carbon feature was left at $284.3 \mathrm{eV}$.

Similar spectra were obtained on $\mathrm{Pt} / \mathrm{NiO}$ for $\mathrm{Ni} 2 \mathrm{p}$ with only differences that after reduction $\mathrm{Ni}^{2+}$ contribution was not detected. The $\mathrm{C} 1 \mathrm{~s}$ due to the template and PVP were removed in oxidation-reduction cycle. The $\mathrm{Pt} 4 \mathrm{f}$ shows mainly $\mathrm{Pt}^{0}$ chemical state; only a small fraction remained in the partially oxidized state.
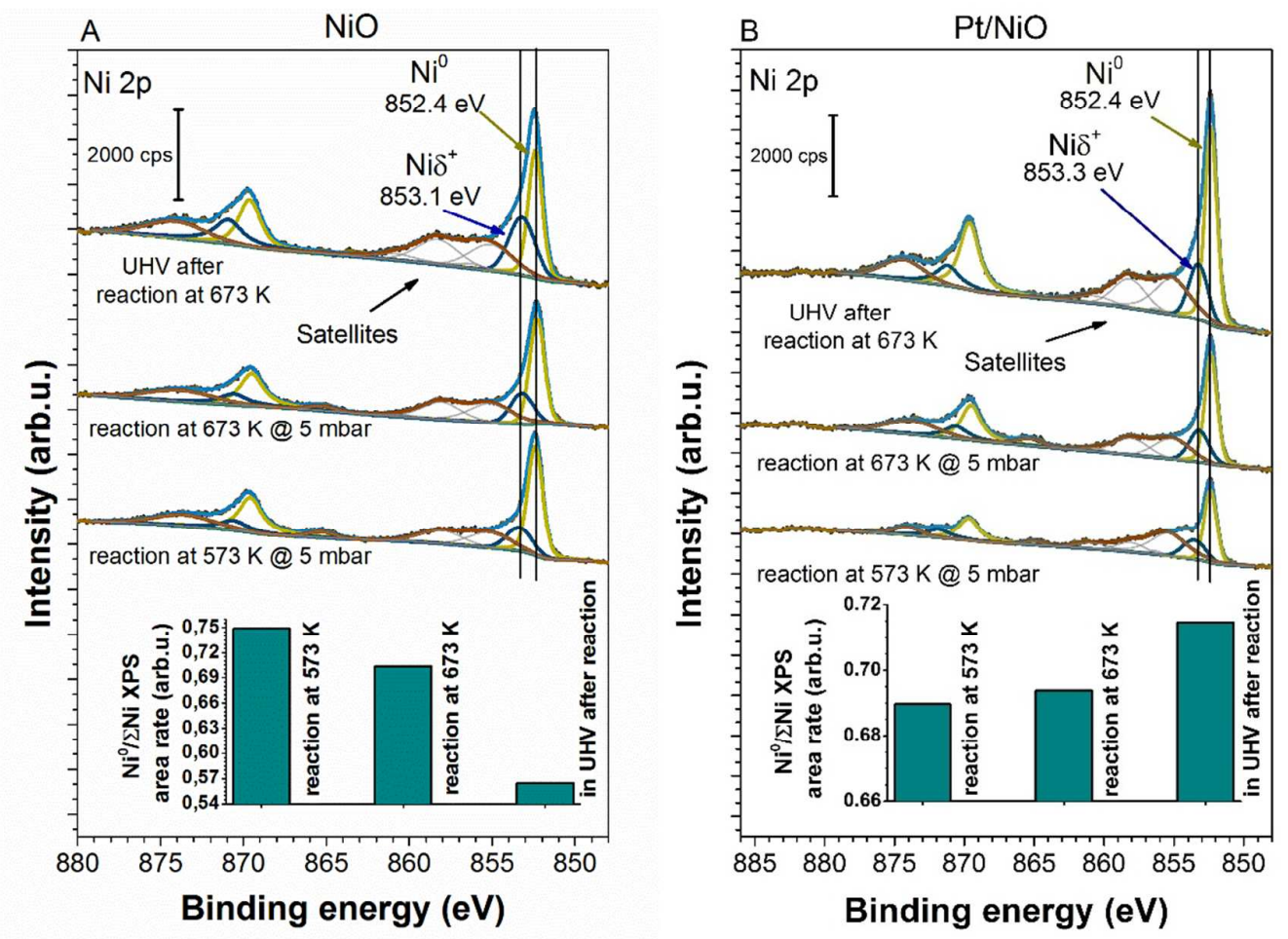

Figure 4. $\mathrm{Ni} 2 \mathrm{p}$ XP spectra of $\mathrm{NiO}(\mathrm{A})$ and $5 \% \mathrm{Pt} / \mathrm{NiO}(\mathrm{B})$ under $\mathrm{CO}_{2}$ hydrogenation conditions and subsequent evacuation at $673 \mathrm{~K}$

Under reaction conditions at $573 \mathrm{~K}-673 \mathrm{~K}$, on the surface of $\mathrm{NiO}$ the $\mathrm{Ni} 2 \mathrm{p}_{3 / 2}$ appeared at $852.4 \mathrm{eV}$ which corresponds to zero valent $\mathrm{Ni}^{0}$ (Fig. 4/A.). A shoulder can be detected at $853.1 \mathrm{eV}$ due to $\mathrm{Ni}^{2+}$ with its satellites at 855.1 and $860.4 \mathrm{eV}$, which are characteristic for $\mathrm{NiO}^{33,35,36}$ the latter one appeared only with very small intensity. Two obvious satellites are fitted by peaks with BE near $856.3 \mathrm{eV}$ (hardly detectable) and at $858.1 \mathrm{eV}$ (major) above the 
main emission of $\mathrm{Ni}^{0}$ at $852.4 \mathrm{eV}$ which is characteristic for metallic $\mathrm{Ni}^{37}$. The satellite for $\mathrm{NiO}$ at $860.4 \mathrm{eV}$ is in well-detectable in the deconvoluted spectrum obtained after vacuum treatment at $673 \mathrm{~K}$ (Fig. 4/A.). In the determination of the ratio of metallic and oxidized fraction we considered all the six emissions in deconvolution in the $\mathrm{Ni} 2 \mathrm{p}_{3 / 2}$ range.

At $5 \mathrm{mbar}$ total pressure and at $573 \mathrm{~K}$, in the case of pure nickel-oxide, the nickel is mainly in reduced state $\left(74 \% \mathrm{Ni}^{0} / \Sigma \mathrm{Ni}\right)$. The metallic nature of the surface became less significant in $\mathrm{CO}_{2}$ hydrogenation at $673 \mathrm{~K}\left(\sim 69 \% \mathrm{Ni}^{0} / \Sigma \mathrm{Ni}\right)$ and the following UHV conditions $(\sim 56 \%)$. These phenomena may be attributed to the fast migration of the oxygen atoms to the surface as well as the slow reoxidation of the elemental nickel on the surface by the adsorbed $\mathrm{CO}_{2}{ }^{38}$ or water ${ }^{39}$.

Beside Ni 2p, C1s and O1s XP signals were also monitored during reaction conditions at 573 and 673 K (Fig. S6. and Fig.S7.). Intense photoemission peaks developed at 292.7 and 291.3 $\mathrm{eV}$ in the case of $\mathrm{C} 1 \mathrm{~s}$ spectra. These peaks can be attributed to gas phase $\mathrm{CO}_{2}$ and gas phase $\mathrm{CO}$ formed in the reaction ${ }^{40}$, respectively. These XPS signals disappeared when the surface was evacuated at 573 or $673 \mathrm{~K}$ (Fig. S6.). It is an important observation that a carbon species remained at $283.2 \mathrm{eV}$ (except adventitious carbon) on the surface after reaction at $573 \mathrm{~K}$. Very likely this peak corresponds to carbidic carbon ${ }^{41,42}$. The origin of this species is the result of decomposition of $\mathrm{CH}_{\mathrm{x}}$. This form markedly decreased on the surface after reaction at $673 \mathrm{~K}$. We suppose in harmony with the literature the carbon on Ni dissolves to the bulk.

This was confirmed by TPR spectroscopy when the used catalyst was heated in hydrogen at a heating rate of $10 \mathrm{~K} \cdot \mathrm{min}^{-1}$. The amount of the carbon was below the detection (not shown). Corresponding $\mathrm{O} 1 \mathrm{~s}$ signals for gas phase $\mathrm{CO}$ and $\mathrm{CO}_{2}$ were detected at 536.4 and $537.6 \mathrm{eV}$, respectively ${ }^{43}$ (Fig. S7.). Besides surface $(531.0 \mathrm{eV})$ and lattice $(530.0 \mathrm{eV})$ oxygen XPS peaks, a relatively broad peak centered at $533 \mathrm{eV}$ was also present. Detailed analysis did not attempt because the DRIFTS give much precise identification of intermediates and adsorbed species. This complex peak may contain formate and different carbonates and adsorbed CO contributions $^{27,44,8}$ which were identified by DRIFTS (see below). After evacuation at $673 \mathrm{~K}$, the intensity of the $\mathrm{O} 1 \mathrm{~s}$ region decreased due to desorption (not shown), but it became more complex as a significant fraction of formate (and formaldehyde) might be transformed to carbonate as independently detected by DRIFTS (see below). Note that the possibility of readsorption from background during evacuation cannot be completely excluded. 


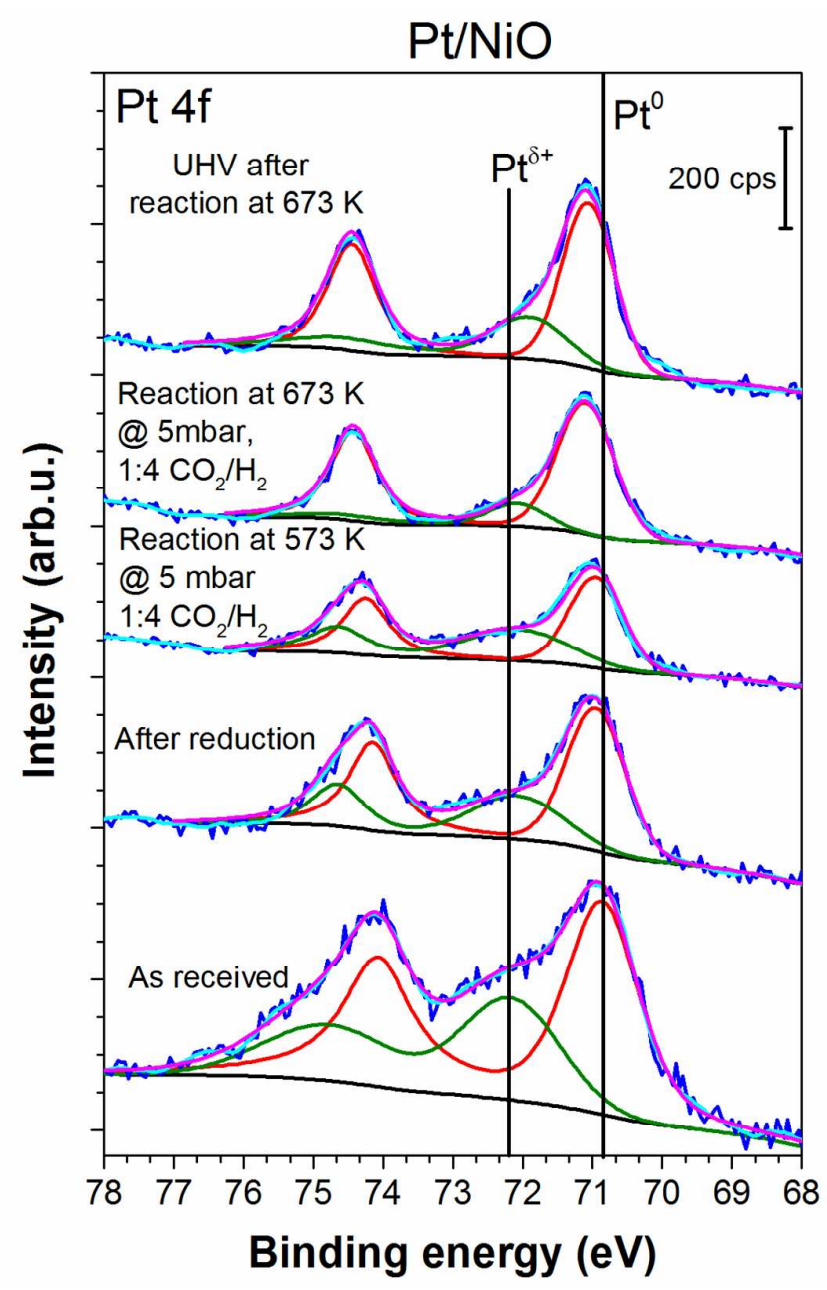

Figure 5. Pt $4 \mathrm{f}$ XPS spectrum of $5 \% \mathrm{Pt} / \mathrm{NiO}$ under pretreatment $\left(\right.$ in $\mathrm{O}_{2}$ and $\mathrm{H}_{2}$ ) as well as reaction conditions at 5 mbar total pressure of $\mathrm{CO}_{2}: \mathrm{H}_{2}$ with a ratio of $1: 4$ at $573 \mathrm{~K}$ and $673 \mathrm{~K}$.

In the case of the $5 \% \mathrm{Pt} / \mathrm{NiO}$ catalyst, the $\mathrm{Ni} 2 \mathrm{p}_{3 / 2}$ was also followed during reactions at 573 and $673 \mathrm{~K}$ and after evacuation at $673 \mathrm{~K}$, respectively (Fig. 4B.). The obtained results are relevant compared to the NAP-XPS studies of the pure NiO catalyst. (In the determination of the ratio of metallic and oxidized fraction we considered all the six emissions of $\mathrm{Ni}$ and $\mathrm{NiO}$ in deconvolution.) During $\mathrm{CO}_{2}$ hydrogenation at $573 \mathrm{~K}$, the surface concentration of metallic nickel is $69 \%$ (Fig. 4B.). In the case of the pure nickel-oxide catalyst, at $673 \mathrm{~K}$ and after reaction at $673 \mathrm{~K}$, the concentration of the $\mathrm{Ni}^{0}$ decreased from $\sim 69 \%$ to $\sim 56 \%$. However, in the case of Pt containing catalyst this trend was opposite. This shows a metallic nickel enrichment on the surface after $\mathrm{CO}_{2}$ hydrogenation at $673 \mathrm{~K}(\sim 69 \%)$. After reaction at $673 \mathrm{~K}$ under UHV condition, the concentration was $\sim 71.5 \%$. Probably, oxygen diffusion from the 
bulk also takes place, where the oxygen atoms from the bulk as well as from the surface of the nickel-oxide support migrate to the Pt nanoparticles helping in the reduction of nickel-oxide. During reaction at $573 \mathrm{~K}$, a small amount of oxidized Pt was observed (Fig. 5.). Under reaction conditions at $673 \mathrm{~K}$, the amount of the oxidized fraction decreased. However, when the catalyst was evacuated at $673 \mathrm{~K}$, the oxidized fraction was regained showing the presence of the oxygen transferring properties of the Pt nanoparticles from the nickel-oxide to the $\mathrm{Pt}$ catalyst. In addition, we may suppose that the enhanced electron transfer from $\mathrm{Pt}$ nanoparticles to $\mathrm{NiO}$ or $\mathrm{Ni} / \mathrm{NiO}$ interface ${ }^{40}$ and oxidation of $\mathrm{Pt}$ nanoparticles by $\mathrm{CO}_{2}$ or $\mathrm{CO}_{2}$ derivatives (carbonate-like surface species) also contribute to the increased oxidized Pt fraction.

The other important observation is that the intensity of $\mathrm{Ni} 2 \mathrm{p}_{3 / 2}$ is increasing with the temperature in the presence of Pt. Besides the reduction of the surface from $\mathrm{NiO}$ to elemental nickel, the bulk $5 \% \mathrm{Pt} / \mathrm{NiO}$ catalyst showed the presence of a high amount of metallic $\mathrm{Ni}$ observed by separate XRD studies (Fig. S8.). Furthermore, a slight sharpening of the Pt (111) diffraction peak was observed showing the aggregation of the Pt nanoparticles during the catalytic reaction resulting in the increase of the Ni $2 p_{3 / 2}$ intensity after reaction. These phenomena show that $\mathrm{Pt}$ assist nickel $(\mathrm{Ni}+\mathrm{NiO})$ enrichment on the surface which is crucial in the activity and selectivity of the catalyst in the hydrogenation of $\mathrm{CO}_{2}$.

On Pt/NiO catalysts the oxidation states of platinum, $\mathrm{Pt} 4 \mathrm{f}_{7 / 2}$ and $\mathrm{Pt} 4 \mathrm{f}_{5 / 2}$ were also monitored (Fig. 5.). The as received sample contains $\mathrm{Pt}^{0}$ and $\mathrm{Pt}^{2+}$ states in 3:1 ratio. After reduction of the catalyst at $573 \mathrm{~K}$, the $4 \mathrm{f}_{5 / 2}$ appeared at $71.1 \mathrm{eV}$ indicating that the platinum is in metallic state $^{45}$. After careful analyzing of the spectrum, a small shoulder could be detected at $71.9 \mathrm{eV}$. This weak shoulder may indicate that a small fraction is in a partially oxidized state probably due to the electronic interaction of $\mathrm{Pt}$ with $\mathrm{Ni} / \mathrm{NiO}$ interface ${ }^{46}$. The final state effect arising from the small particles size ${ }^{47}$ probably can be ruled out because the particle sizes of Pt did not change during the reaction and after vacuum treatment according to our HRTEM experiments. Carbon XPS signal was hardly detectable after high temperature evacuation. TPR spectroscopy was able to detect a small amount of methane formation $\left(T_{p}=600 \mathrm{~K}\right)$ when the used catalyst was heated in hydrogen (not shown).

The carbon and oxygen signals during the reaction were identical with that obtained with pure nickel oxide catalyst. Typical O 1s obtained on $\mathrm{Pt} / \mathrm{NiO}$ in the reaction is shown in Fig. S7/B. The freshly reduced Pt surface is very active, so CO adsorption always occurs from the background in a certain amount. Therefore, we focus to the spectra obtained under reaction 
conditions (573 and $673 \mathrm{~K}$ ). It is remarkable that when increasing the reaction temperature, the intensities of lattice oxygen $(530.1 \mathrm{eV})$ and surface oxygen $(531.1 \mathrm{eV})$ slightly decreased due to the further reduction of $\mathrm{NiO}$. Peaks at 537.6 and $536.4 \mathrm{eV}$ corresponds to gas phase $\mathrm{CO}_{2}$ and $\mathrm{CO}$, respectively ${ }^{43}$. A broad peak between 531 and $535 \mathrm{eV}$ may compose $\mathrm{C}=\mathrm{O}$ bonded species (probably formaldehyde), adsorbed $\mathrm{CO}$ and adsorbed formate and carbonate intermediates (which were identified by DRITS; see below). After evacuation at $673 \mathrm{~K}$, the intensities of gas phase components $\left(\mathrm{CO}\right.$ and $\left.\mathrm{CO}_{2}\right)$ drastically decreased. The intensities of other components decreased only slightly (not shown).

\section{$\underline{3.5 \text { Infrared spectra during } \mathrm{CO}_{2}} \underline{\text { hydrogenation at elevated temperatures }}$}

For catalytic reactions, the exploration of surface species formed during the catalytic processes plays a decisive role in the understanding of the reaction mechanism. Towards this goal, DRIFT spectra were monitored at increasing reaction temperatures, in the presence of the reactant mixture/products. In all cases the different catalysts were pretreated in oxygen at $573 \mathrm{~K}$ followed by reduction in $\mathrm{H}_{2}$ at $573 \mathrm{~K}$. The assignment of IR bands and the detailed description is based on the vibrational fingerprints of relevant surface species, which were reported in previous publications. The IR bands observed during the present work and their origins are collected in Table 1 . Note that the denoted wave numbers may vary by $\pm 5 \mathrm{~cm}^{-1}$ within one data set as a function of temperature.

When the reaction mixture was introduced to the Pt-free SBA-15, no adsorption forms were detected at any temperatures. The DRIFT spectra for 5\% 5nm Pt/SBA-15 in the $\mathrm{CO}_{2}: \mathrm{H}_{2}$ mixture are shown in Fig. S9. The band at $2072 \mathrm{~cm}^{-1}$ started to develop already at $300 \mathrm{~K}$. From $373 \mathrm{~K}$, the intensity increased and it was present even at high temperature ( $723 \mathrm{~K})$. This peak is attributed to the formation of adsorbed $\mathrm{CO}$ which forms during the catalytic reaction. This kind of $\mathrm{CO}$ bonds to the Pt particles in linear form ${ }^{48,49}$. This peak was also detected when the Pt content was $1 \%$ in the case of the Pt/SBA-15 catalysts (not shown). In that case the peak corresponding to the linear $\mathrm{CO}$ appeared first at $423 \mathrm{~K}$ with lower intensity. No other absorption band for adsorbed $\mathrm{CO}$ was detected. The linearly adsorbed $\mathrm{CO}$ form appeared when $\mathrm{CO}$ was introduced to this surface at $300 \mathrm{~K}$, too. 
Table 1. Characteristic frequencies $\left( \pm 5 \mathrm{~cm}^{-1}\right)$ for surface intermediates formed in the $\mathrm{CO}_{2}+$ $\mathrm{H}_{2}$ reaction on pure $\mathrm{NiO}, \mathrm{Pt} / \mathrm{NiO}$ and $\mathrm{Pt} / \mathrm{SBA}-15$ catalysts

\begin{tabular}{|c|c|c|c|c|c|c|}
\hline Intermediates & $\begin{array}{l}\text { Vibration } \\
\text { mode }\end{array}$ & $\mathrm{NiO}$ & $\begin{array}{c}1 \% \\
\mathrm{Pt} / \mathrm{NiO}\end{array}$ & $\begin{array}{c}5 \% \mathrm{Pt} / \\
\mathrm{NiO}\end{array}$ & $\begin{array}{c}\text { Pt/ } \\
\text { SBA- } \\
15\end{array}$ & Ref. \\
\hline $\begin{array}{l}\text { bidentate } \\
\text { carbonate } \\
\mathrm{CO}_{3}^{-}\end{array}$ & $\begin{array}{l}v_{3}(\mathrm{O}-\mathrm{C}-\mathrm{O})_{\mathrm{a}} \\
v_{3}(\mathrm{O}-\mathrm{C}-\mathrm{O})_{\mathrm{s}}\end{array}$ & $\begin{array}{l}1302 \\
1383 \\
1538 \\
1620 \\
\end{array}$ & $\begin{array}{l}1305 \\
1576\end{array}$ & $\begin{array}{l}1305 \\
1530\end{array}$ & & 50,51 \\
\hline $\begin{array}{l}\text { bicarbonate } \\
\mathrm{HCO}_{3}^{-}\end{array}$ & $\begin{array}{c}v_{2}(\mathrm{O}-\mathrm{C}-\mathrm{O})_{\mathrm{a}} \\
v_{3}(\mathrm{O}-\mathrm{C}-\mathrm{O})_{\mathrm{s}} \\
\delta(\mathrm{COH})\end{array}$ & $\begin{array}{l}1648 \\
1375 \\
1214\end{array}$ & $\begin{array}{l}1630 \\
1378 \\
1214\end{array}$ & $\begin{array}{l}1626 \\
1376 \\
1214\end{array}$ & & 51 \\
\hline $\begin{array}{l}\text { carbon } \\
\text { monoxide } \\
\mathrm{CO}\end{array}$ & $\begin{array}{l}\text { linear } \\
\text { bridge }\end{array}$ & & $\begin{array}{c}2052 \\
1912 \\
\text { (weak) }\end{array}$ & $\begin{array}{l}2061 \\
1918\end{array}$ & $\begin{array}{l}2078 \\
1940\end{array}$ & $\begin{array}{c}48,49, \\
52\end{array}$ \\
\hline $\begin{array}{l}\text { carbonyl } \\
\text { hydrides } \\
\mathrm{H}_{\mathrm{n}} \mathrm{CO}(\mathrm{n}=1,2)\end{array}$ & & $\begin{array}{c}1880 \\
\text { (weak) }\end{array}$ & $\begin{array}{c}1840 \\
\text { (strong) }\end{array}$ & $\begin{array}{c}1840 \\
\text { (weak) }\end{array}$ & 1817 & $\begin{array}{l}21,53, \\
19,54\end{array}$ \\
\hline $\begin{array}{l}\text { formaldehyde } \\
\mathrm{H}_{2} \mathrm{CO}\end{array}$ & $\begin{array}{l}\nu \mathrm{CO} \\
v \mathrm{CH}\end{array}$ & $\begin{array}{c}1770 \\
\text { (weak) }\end{array}$ & - & $\begin{array}{c}1770 \\
\text { (strong) } \\
2840 \\
\end{array}$ & & $\begin{array}{l}55,56, \\
57,58\end{array}$ \\
\hline $\begin{array}{l}\text { formate } \\
\mathrm{HCOO}^{-}\end{array}$ & $\begin{array}{c}v_{\mathrm{a}}(\mathrm{OCO}) \\
v_{\mathrm{S}}(\mathrm{OCO}) \\
\gamma(\mathrm{OCO}) \\
v \mathrm{CH}\end{array}$ & $\begin{array}{l}1576 \\
1340 \\
\\
2837\end{array}$ & $\begin{array}{l}1572 \\
1376\end{array}$ & $\begin{array}{l}1576 \\
1350 \\
1379 \\
2838\end{array}$ & 2840 & $\begin{array}{l}59,60, \\
61,57\end{array}$ \\
\hline
\end{tabular}

The evaluation of the low wavenumber region of Pt/SBA-15 is particularly difficult, since the silica-like sample itself has very strong absorptions at $\sim 1940, \sim 1820-1570$ and $\sim 1200-1000$ $\mathrm{cm}^{-1} 52$. Although these features should be accounted for by the background spectrum, they might also change as a function of temperature and thus disturb our spectra. We tentatively assign the features observed to this effect. We cannot exclude that a small absorption bands at 1942 and $1825 \mathrm{~cm}^{-1}$ reflect the appearance of bridge bonded $\mathrm{CO}^{62}$. The latter could be influenced by adsorbed hydrogen. This feature was also detected on $\mathrm{Rh} / \mathrm{SiO}_{2}{ }^{21}$. The lowfrequency shift in the presence of hydrogen has been attributed to the formation of Rh carbonyl hydrides ${ }^{53,63,54}$. It is assumed that the $\mathrm{CO}$ in this complex could easily dissociate. It is important to mention that $\mathrm{C}-\mathrm{H}$ stretching was not observed (Fig. S9.). These phenomena correlate with the catalytic tests, where the SBA-15 supported Pt nanoparticles produced 
mainly $\mathrm{CO}$ and almost no other products. At the $\mathrm{Pt} / \mathrm{SiO}_{2}$ interfaces, the reverse-water-shift gas (RWSG) reaction resulted in the formation of $\mathrm{CO}$ from $\mathrm{CO}_{2}{ }^{27}$.

$$
\begin{gathered}
\mathrm{H}_{2(\mathrm{~g})} \rightarrow 2 \mathrm{H}_{(\mathrm{a})} \\
\mathrm{CO}_{2(\mathrm{~g})} \rightarrow \mathrm{CO}_{2(\mathrm{a})}{ }^{*} \\
\mathrm{CO}_{2(\mathrm{a})}{ }^{*}+\mathrm{H}_{(\mathrm{a})} \rightarrow \mathrm{HOCO}_{(\mathrm{a})}{ }^{*} \\
\mathrm{HOCO}_{(\mathrm{a})}{ }^{*}+\mathrm{H}_{(\mathrm{a})} \rightarrow \mathrm{CO}_{(\mathrm{a})}+\mathrm{H}_{2} \mathrm{O}_{(\mathrm{a})} \rightarrow \mathrm{CO}_{(\mathrm{g})}+\mathrm{H}_{2} \mathrm{O}_{(\mathrm{g})}
\end{gathered}
$$
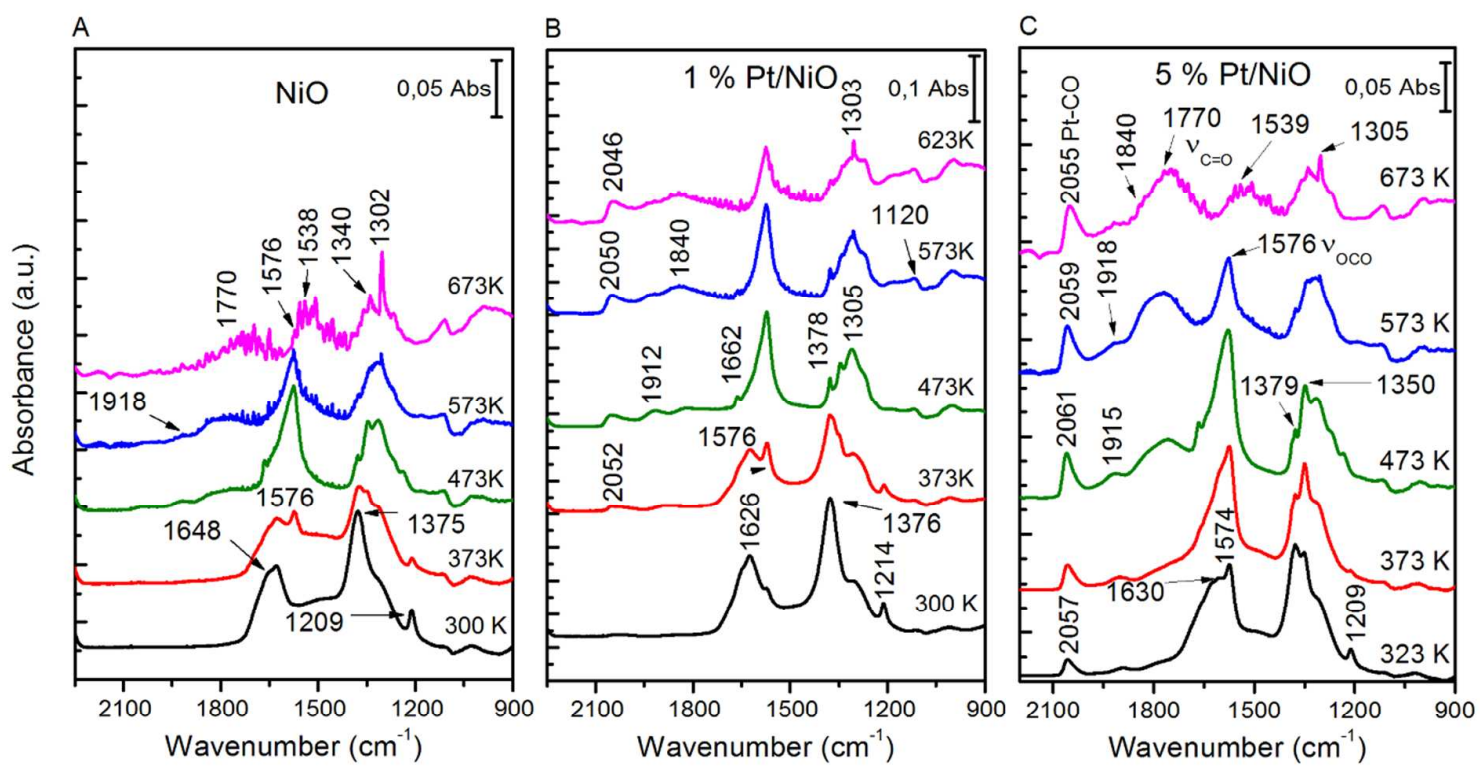

Figure 6. DRIFT spectra obtained during linear heating $\left(20 \mathrm{~K} \cdot \mathrm{min}^{-1}\right)$ in $\mathrm{CO}_{2}: \mathrm{H}_{2}$ mixture $(1: 4)$ on $\mathrm{NiO}(\mathrm{A}), 1 \% \mathrm{Pt} / \mathrm{NiO}(\mathrm{B})$ and $5 \% \mathrm{Pt} / \mathrm{NiO}(\mathrm{C})$ catalysts (average $\mathrm{Pt}$ particle size is $4.8 \mathrm{~nm}$ ).

When $\mathrm{CO}_{2}: \mathrm{H}_{2}$ mixture was introduced to the pretreated $\mathrm{NiO}$ catalyst, a broad band appeared at $1648 \mathrm{~cm}^{-1}$ and two narrow ones at 1375 and $1209 \mathrm{~cm}^{-1}$ at $300 \mathrm{~K}$, as represented in Fig. 6/A. These bands correspond to the bicarbonate $\left(\mathrm{HCO}_{3}{ }^{-}\right)$species and can be assigned to $v_{2}(\mathrm{OCO})_{\mathrm{a}}$, $v_{3}(\mathrm{OCO})_{\mathrm{s}}$ and $\delta_{4}(\mathrm{COH})$, respectively ${ }^{51}$. The adsorption of $\mathrm{CO}_{2}$ on $\mathrm{NiO}$ gives two adsorption bands in the IR spectrum at 1620 and $1383 \mathrm{~cm}^{-1}$ (not shown), which are assigned to carbonate ion on the oxide ${ }^{50}$. Carbonate structures may be formed via coordination of a bent $\mathrm{CO}_{2}{ }^{\delta-}$ towards an oxygen atom ${ }^{64}$.

When the sample was heated to $473 \mathrm{~K}$, two peaks developed at 1576 and $1340 \mathrm{~cm}^{-1}$. These bands can be assigned to the formation of formate species. These species were observed on 
$\mathrm{Rh} / \mathrm{MgO}$ catalyst during $\mathrm{CO}_{2}: \mathrm{H}_{2}$ adsorption ${ }^{19}$, and after adsorption of $\mathrm{HCOOH}$ on $\mathrm{TiO}_{2}$ powder ${ }^{59,60}$ and $\mathrm{TiO}_{2}(110)^{61}$ due to asymmetric and symmetric stretch of (OCO). The corresponding $v(\mathrm{CH})$ vibration is detected at $2837 \mathrm{~cm}^{-1}$ from $473 \mathrm{~K}$ (Fig. S9/A.). Around 473 $\mathrm{K}$ a weak band appeared at $1875-1900 \mathrm{~cm}^{-1}$ probably due hydrogen perturbed $\mathrm{CO}$.

When the sample was further heated (573-673 K), the intensity of C-H stretching vibrational features decreased. Two peaks remained or developed at 1576 and $1302 \mathrm{~cm}^{-1}$, very probably due to asymmetric and symmetric bidentate carbonates $\left(v_{3}(\mathrm{OCO})_{\mathrm{a}}\right.$ and $\left.v_{3}(\mathrm{OCO})_{\mathrm{s}}\right)$. A broad, weak peak at around $1770 \mathrm{~cm}^{-1}$ is detectable as $\mathrm{C}=\mathrm{O}$ containing species $\left(\mathrm{H}_{2} \mathrm{CO}\right)$. Also a weak absorption band is detectable at $1918 \mathrm{~cm}^{-1}$ due to hydrogen perturbed $\mathrm{CO}$, which is located on metallic Ni. From $573 \mathrm{~K}$ a sharp peak for gas phase $\mathrm{CH}_{4}$ was detected indicating that the reaction between $\mathrm{CO}_{2}$ and $\mathrm{H}_{2}$ is occurring (Fig. $\mathrm{S} 10 /$ A.).

When $4.8 \mathrm{~nm}$ Pt nanoparticles were anchored onto $\mathrm{NiO}$ at different content, new spectral features were observed. The bicarbonate-formate-bidentate carbonate surface reaction sequence remained in the $300-623 \mathrm{~K}$ temperature range. In the case of the $1 \% \mathrm{Pt} / \mathrm{NiO}$ catalyst, peaks at $1576,1378 \mathrm{~cm}^{-1}$ may represent the formate in $v_{\text {assym }}(\mathrm{OCO})$ and $v_{\mathrm{s}}(\mathrm{OCO})$ modes, respectively $^{65}$ (Fig. 6/B.). As new feature, linearly adsorbed CO at 2046-2061 $\mathrm{cm}^{-1}$ appeared already at room temperature. Small intensity bridge bonded CO showed up at 1915-1918 and $1840 \mathrm{~cm}^{-1}$. The latter species is presumably CO perturbed by adsorbed hydrogen.

It is clear that the Pt adatom catalyzes the transformation of bicarbonate to formate; peak at $\sim 1630 \mathrm{~cm}^{-1}$ (bicarbonate) is hardly detectable at $373 \mathrm{~K}$ in the case of $5 \% \mathrm{Pt} / \mathrm{NiO}$ sample (Fig. 6/C.). The corresponding $v(\mathrm{CH})$ vibration at $2837-40 \mathrm{~cm}^{-1}$ is detectable already at $323-$ $373 \mathrm{~K}$ (Fig. S/10.). The detection of a strong CO signal indicates that the $\mathrm{Pt}$ is an active center for the dissociation of $\mathrm{CO}_{2}$ in the presence of hydrogen. Without hydrogen the formation of adsorbed $\mathrm{CO}$ was not observed. The appearance of gas phase $\mathrm{CH}_{4}$ in FTIR spectra above 473 $\mathrm{K}$ demonstrates that a catalytic reaction occurs between $\mathrm{CO}_{2}$ and hydrogen. The bands for adsorbed $\mathrm{CO}$ and $\mathrm{CH}$ and for gas phase methane (Fig. S10/B., S10/C.) appeared at higher temperature at low (1\%) Pt content. Independently from the Pt content, an IR band was observed at $1840 \mathrm{~cm}^{-1}$, which was probably due to $\mathrm{CO}$ perturbed by hydrogen: so-called carbonyl hydrides ${ }^{21,54}$. BOC-MP calculations have also shown that the dissociation of $\mathrm{H}_{\mathrm{n}} \mathrm{CO}$, where $\mathrm{n}=1,2$ or 3 is energetically more favorable than the direct dissociation of $\mathrm{CO}$ on $\mathrm{Pd}$ and $\mathrm{Pt}^{66}$. Although there is significant evidence to support the idea that $\mathrm{C}-\mathrm{O}$ bond cleavage is hydrogen assisted, no direct evidence for the existence of $\mathrm{H}_{\mathrm{n}} \mathrm{CO}$ surface species during the hydrogenation of $\mathrm{CO}$ or $\mathrm{CO}_{2}$ has been reported. Williams et al. ${ }^{67}$ have proposed a mechanism 
for $\mathrm{CO}_{2}$ hydrogenation to methane over $\mathrm{Rh}$ based on the observations reported above in which $\mathrm{H}_{2} \mathrm{CO}_{(\mathrm{a})}$-like species is involved. Its decomposition leads to $\mathrm{CH}_{2(\mathrm{a})}$ which either forms carbon or is hydrogenated to $\mathrm{CH}_{4}$.

A significantly strong absorption feature at $1770 \mathrm{~cm}^{-1}$ is detected at $5 \% \mathrm{Pt}$ content (Fig. 6/C.). This band corresponds to the $\mathrm{C}=\mathrm{O}$ double bond, thus it can be assigned to formaldehyde $(\mathrm{vCO})$. This peak was observed in gas phase formaldehyde ${ }^{68}$, after adsorption of formaldehyde on $\mathrm{NiO}^{55}$, on $\mathrm{TiO}_{2}$-supported $\mathrm{Rh}^{56}$ and $\mathrm{Pt}$ and Au catalysts ${ }^{57}$. It is evident that the formation of formyl/formaldehyde species is catalyzed by Pt particles in $\mathrm{CO}_{2}: \mathrm{H}_{2}$ reaction, because it was difficult to detect on clean $\mathrm{NiO}$. As this intermediate is still present even at high temperature $(673 \mathrm{~K})$, we may suppose that its formation rate is higher than its decomposition rate. Very probably the formyl $\left(\mathrm{H}_{2} \mathrm{CO}\right)$ species could decompose to the final products. Mainly at 5\% Pt content, we have two important IR peaks, that can both be assigned to hydrogen. It is perturbated $\mathrm{CO}$ : one is $\mathrm{H}_{2} \mathrm{CO}_{(\mathrm{a})}-$ like species or carbonyl hydrides at 1840 $\mathrm{cm}^{-1}$, the other is of formyl/formaldehyde, at $1770 \mathrm{~cm}^{-1}$ which contains $\mathrm{C}=\mathrm{O}$ double bond. Both of them could be important in the $\mathrm{CO}_{2}: \mathrm{H}_{2}$ reaction. It is clear that the carbonyl hydrides are more reactive. $\mathrm{vCH}_{2}$ was detected even at $323-373 \mathrm{~K}$ indicating that in this case (compare to the Pt-free case) some hydrocarbon fragment, very probably formate is formed (Fig. S10/B., S10/C.). Gas phase methane appeared already from $523 \mathrm{~K}$. The $\mathrm{H}_{2} \mathrm{CO}_{(\text {a) }}$ is rather stable, its contribution to the gas phase products is less than the hydrogen perturbed CO. The question arises: what is the source of the formation of formyl/formaldehyde detected on $\mathrm{Pt} / \mathrm{NiO}$ ? Recently it was found that formaldehyde forms in the interaction of $\mathrm{HCOOH}$ with $\mathrm{Pt}$ supported $\mathrm{TiO}_{2}{ }^{58}$. In this interaction it was supposed that both vacancies and $\mathrm{Pt}$ sites catalyze formaldehyde formation. It is important that the formate is produced on pure $\mathrm{NiO}$, and the hydrogen is dissociating on Pt nanoparticles. We may assume that hydrogen atoms migrate to the metal-support interface and react with formate there to form formyl/formaldehyde. As adsorbed formyl was not detectable at low Pt content, we suppose that large amount of atomic hydrogen is necessary for this reaction. Though the dissociation of hydrogen takes place at $300 \mathrm{~K}$, formyl forms from $423 \mathrm{~K}$ at 5\% Pt content, indicating that the hydrogen spillover from the metal to $\mathrm{NiO}$ or its reaction with formate is an activated process. This type of formyl could then decompose to $\mathrm{CO}$ at higher temperatures ${ }^{57}$.

Taking into account the product distribution in the $\mathrm{CO}_{2}: \mathrm{H}_{2}$ reaction and the observed intermediates on $\mathrm{NiO}$ and $\mathrm{Pt} / \mathrm{NiO}$ catalysts we may assume that the reversed water gas shift mechanism (RWGS) to form CO is also valid in a certain extent (steps 1-4). The methane 
formation can be deduced through formation of surface $\mathrm{H}_{n} \mathrm{CO}(n=1,2,3)$ which was offered on supported $\mathrm{Pt}^{21}$ and $\mathrm{Rh}^{18}$ catalysts:

$$
\begin{gathered}
\mathrm{CO}_{(\mathrm{a})}+\mathrm{nH}_{(\mathrm{a})} \rightarrow \mathrm{H}_{\mathrm{n}}(\mathrm{CO})_{(\mathrm{a})} \\
\mathrm{H}_{\mathrm{n}}(\mathrm{CO})_{(\mathrm{a})} \rightarrow \mathrm{CH}_{\mathrm{n}(\mathrm{a})}+\mathrm{O}_{(\mathrm{a})} \\
\mathrm{O}_{(\mathrm{a})}+2 \mathrm{H}_{(\mathrm{a})} \rightarrow \mathrm{OH}_{(\mathrm{a})}+\mathrm{H}_{(\mathrm{a})} \rightarrow \mathrm{H}_{2} \mathrm{O}_{(\mathrm{g})} \\
\mathrm{CH}_{\mathrm{n}(\mathrm{a})}+\mathrm{H}_{(\mathrm{a})} \rightarrow \mathrm{CH}_{4(\mathrm{~g})}
\end{gathered}
$$

The reaction steps 5-8 could be dominant at $1 \% \mathrm{Pt}$ content. The $\mathrm{CH}_{\mathrm{n}}$ species may recombine a small extent to form ethane.

On Pt-free NiO, the formate pathways come to the front as formate is the main surface intermediate observed in DRIFTS:

$$
\begin{gathered}
\mathrm{CO}_{2(\mathrm{a})}{ }^{*}+\mathrm{H}_{(\mathrm{a})} \rightarrow \mathrm{HCOO}_{(\mathrm{a})} \\
\mathrm{HCOO}_{(\mathrm{a})} \rightarrow \mathrm{CO}_{(\mathrm{a})}+\mathrm{OH}_{(\mathrm{a})} \rightarrow \mathrm{CO}_{(\mathrm{g})}+\mathrm{H}_{2} \mathrm{O}_{(\mathrm{g})}
\end{gathered}
$$

The formate intermediate may produce methane, $\operatorname{too}^{19}$ :

$$
\begin{aligned}
\mathrm{HCOO}_{(\mathrm{a})} & \rightarrow \mathrm{H}_{2} \mathrm{COH}_{(\mathrm{a})} \rightarrow \mathrm{H}_{2} \mathrm{C}_{(\mathrm{a})}+\mathrm{OH}_{(\mathrm{a})} \\
\mathrm{H}_{2} \mathrm{C}_{(\mathrm{a})}+2 \mathrm{H}_{(\mathrm{a})} & \rightarrow \mathrm{CH}_{4(\mathrm{~g})}
\end{aligned}
$$

When the Pt content is high, the formate may convert to formaldehyde as was observed in our DRIFTS experiments and published on $\mathrm{Pt} / \mathrm{SiO}_{2}$ and $\mathrm{Pt} / \mathrm{TiO}_{2}{ }^{21,44}$ :

$$
\mathrm{HCOO}_{(\mathrm{a})}+\mathrm{Pt} \rightarrow \mathrm{H}_{2} \mathrm{CO}_{(\mathrm{a})}+\mathrm{Pt}-\mathrm{O}
$$

The formaldehyde may decompose to $\mathrm{CO}^{44}$ at high temperature but may forms $\mathrm{CH}_{4}{ }^{21}$, too ${ }^{69}$ :

$$
\begin{gathered}
\mathrm{H}_{2} \mathrm{CO}_{(\mathrm{a})} \rightarrow \mathrm{CO}_{(\mathrm{g})}+\mathrm{H}_{2(\mathrm{~g})} \\
\mathrm{H}_{2} \mathrm{CO}_{(\mathrm{a})}+2 \mathrm{H}_{(\mathrm{a})} \rightarrow \mathrm{CH}_{3(\mathrm{a})}+\mathrm{OH}_{(\mathrm{a})} \\
\mathrm{CH}_{3(\mathrm{a})}+\mathrm{H}_{(\mathrm{a})} \rightarrow \mathrm{CH}_{4}
\end{gathered}
$$

In summary, from the XPS measurements we may conclude that the $\mathrm{CO}_{2}$ hydrogenation at $573 \mathrm{~K}$ and $673 \mathrm{~K}$ takes place on the surface and interface of a complex $\mathrm{NiO}_{\mathrm{x}} / \mathrm{Ni} / \mathrm{PtO} \mathrm{x} / \mathrm{Pt}$ 
catalyst. Pt boosts oxygen migration to the surface as well as changes the reaction mechanism and activity, resulting in a high performance $\mathrm{CH}_{4}$ producing catalyst with $1 \% 4.8 \mathrm{~nm} \mathrm{Pt}$ nanoparticles on the surface of the mesoporous nickel oxide support (Fig. 7A).

In the case of pure nickel-oxide during $\mathrm{CO}_{2}$ hydrogenation over $673 \mathrm{~K}$, small amounts of formaldehyde and hydrogen perturbated $\mathrm{CO}$ are present at the surface to form mostly methane observed by DRIFTS studies. In the case of the most active and methane selective $1 \% \mathrm{Pt} / \mathrm{NiO}$ sample, formaldehyde species are absent but a significant amount of hydrogen perturbated CO is present. The number of perturbing hydrogen atoms are even higher (2-3) compared to pure $\mathrm{NiO}$ catalyst (1-2). These results show, that the presence of Pt helps to produce the high numbered hydrogen perturbated $\mathrm{CO}$ complex, which in turn is producing methane in the $\mathrm{CO}_{2}$ hydrogenation reaction. The formation of formaldehyde does not help methane formation process (Fig. 7/B.).

A

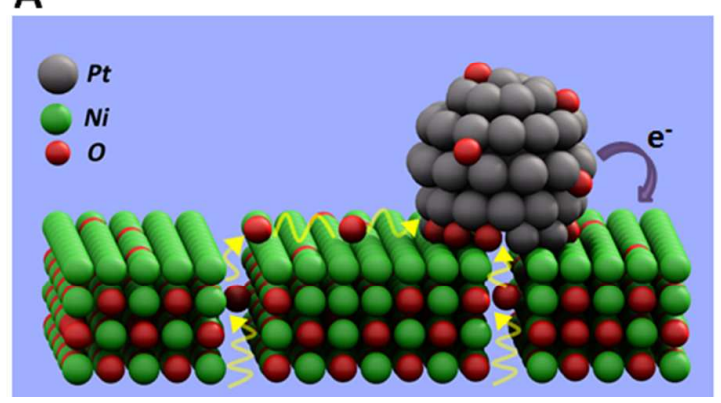

B

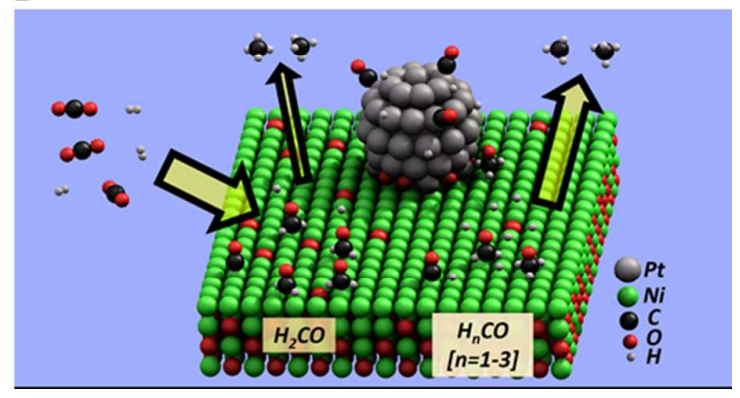

Figure 7. (A) Schematic view of a presence of complex $\mathrm{NiO}_{\mathrm{x}} / \mathrm{Ni} / \mathrm{PtO} \mathrm{x}_{\mathrm{x}} / \mathrm{Pt}$ catalyst, where $\mathrm{Pt}$ boosts oxygen migration to the surface; (B) Schematic view of the proposed mechanism of $\mathrm{CO}_{2}$ hydrogenation over hydrogen perturbated $\mathrm{CO}$, where $\mathrm{Pt}$ flood the surface with hydrogen to enhance the $\mathrm{CH}_{4}$ formation.

\section{CONCLUSION}

Here in this project, size controlled Pt nanoparticles with $4.8 \mathrm{~nm}$ diameter were anchored onto the surface of 3D mesoporous nickel-oxide support. $\mathrm{Pt} / \mathrm{NiO}$, pristine $\mathrm{NiO}$ as well as $\mathrm{Pt}$ supported on SBA-15 catalysts were tested in $\mathrm{CO}_{2}$ hydrogenation reaction in the gas phase in a flow reactor at $473-673 \mathrm{~K}$ as well as investigated with Temperature Programmed Reduction (TPR). The catalysts were also monitored under reaction conditions with Near 
Ambient Pressure X-ray Photoelectron Spectroscopy (NAP-XPS) as well as in-situ Diffuse Reflectance Infrared Fourier Transform Spectroscopy (DRIFTS).

$1 \% \mathrm{Pt} / \mathrm{NiO}$ was $\sim 20$ times and $\sim 1.5$ times more active at $493 \mathrm{~K}$ compared to Pt/SBA-15 and $\mathrm{NiO}$ catalysts, respectively. However, the Pt-free $\mathrm{NiO}$ support has an activity of $120 \%$ compared to $\mathrm{Pt} / \mathrm{NiO}$ catalysts at $673 \mathrm{~K}$. In the case of $1 \% \mathrm{Pt} / \mathrm{SBA}-15$ catalyst, selectivity towards methane was $13 \%$, while it was $90 \%$ and $98 \%$ for $\mathrm{NiO}$ and $1 \% \mathrm{Pt} / \mathrm{NiO}$ at $673 \mathrm{~K}$, respectively.

In the case of pure $\mathrm{NiO}$, we found that the surface of the support was mainly covered by elemental $\mathrm{Ni}$ under reaction conditions, where the $\mathrm{Ni} / \mathrm{NiO}_{\mathrm{x}}$ system is responsible for the high activity of Pt-free catalyst. In the case of $\mathrm{Pt} / \mathrm{NiO}$, $\mathrm{Pt}$ improves the reduction of $\mathrm{NiO}_{\mathrm{x}}$ towards metallic Ni. We found oxidized Pt at $673 \mathrm{~K}$ with XPS at 5\% Pt content showing the presence of a $\mathrm{Pt} / \mathrm{PtO}_{\mathrm{x}} / \mathrm{Ni} / \mathrm{NiO}_{\mathrm{x}}$ mixed phase, where the different interfaces may be responsible for the high activity and selectivity towards methane.

In the case of pure $\mathrm{NiO}$ under reaction condition, formaldehyde as well as a small amount hydrogen perturbated $\mathrm{CO}$ was detected. However, in the case of $1 \% \mathrm{Pt} / \mathrm{NiO}$, significant amounts of $\mathrm{H}_{n} \mathrm{CO}$ species were presented on the surface showing that the reaction towards methane goes through the dissociation of $\mathrm{H}_{n} \mathrm{CO}$ on the surface. The formyl/formaldehyde form could be a rather inactive intermediate due to its high thermal stability.

\section{ACKNOWLEDGEMENT}

This paper was supported by the János Bolyai Research Scholarship of the Hungarian Academy of Sciences as well as the Hungarian Research Development and Innovation Office through grants NKFIH OTKA PD 120877 of AS. ÁK, GH and KZ are grateful for the fund of NKFIH (OTKA) K1 12531 \& NN110676, PD 115769 and K120115, respectively. This collaborative research was partially supported by the "Széchenyi 2020 " program in the framework of GINOP-2.3.2-15-2016-00013 "Intelligent materials based on functional surfaces - from syntheses to applications" project. NAP-XPS measurements were governed in in Prage, Charles University under the program of Ceric-Eric Consortium. 


\begin{abstract}
ASSOCIATED CONTENT
Supporting Information.

Detailed experimental procedures and supplementary figures and table. This material is available free of charge via the Internet at http://pubs.acs.org.
\end{abstract}

\title{
AUTHOR INFORMATION
}

\section{Corresponding Author}

*sapia@chem.u-szeged.hu

\section{Author Contributions}

\$These authors contributed equally.

\section{REFERENCES}

(1) Chiang, J. H.; Hopper, J. R. Kinetics of the Hydrogenation of Carbon Dioxide over Supported Nickel. Ind. Eng. Chem. Prod. Res. Dev. 1983, 22, 225-228.

(2) Vannice, M. A. The Catalytic Synthesis of Hydrocarbons from $\mathrm{H}_{2} / \mathrm{CO}$ Mixtures over the Group VIII Metals II. The Kinetics of the Methanation Reaction over Supported Metals. J. Catal. 1975, 37 (3), 462-473.

(3) Schlutter, M.; Götz, M.; Lefebre, J.; Prabhakaran, P.; Schneider, J.; Rönsch, S.; Matthischkle, S.; Bajorh, S. Review on Methanation - From Fundamentals to Current Projects. Fuel 2015, 166, 276-296.

(4) Li, C.-S.; Melaet, G.; Ralston, W. T.; An, K.; Brooks, C.; Ye, Y.; Liu, Y.-S.; Zhu, J.; Guo, J.; Alayoglu, S.; et al. High-Performance Hybrid Oxide Catalyst of Manganese and Cobalt for Low-Pressure Methanol Synthesis. Nat. Commun. 2015, 6, 6538.

(5) Giesbrecht, P. K.; Herbert, D. E. Electrochemical Reduction of Carbon Dioxide to Methanol in the Presence of Benzannulated Dihydropyridine Additives Electrochemical Reduction of Carbon Dioxide to Methanol in the Presence of Benzannulated Dihydropyridine Additives. ACS Energy Lett. 2017.

(6) Boston, D. J.; Xu, C.; Armstrong, D. W.; Macdonnell, F. M. Photochemical Reduction of Carbon Dioxide to Methanol and Formate in a Homogeneous System with 
Pyridinium Catalysts. J. Am. Chem. Soc. 2013, 135, 16252-16255.

(7) Sápi, A.; Varga, A.; Samu, G. F.; Dobó, D. G.; Juhász, K. L.; Takacs, B.; Varga, E.; Kukovecz, A.; Kónya, Z.; Janáky, C. Photoelectrochemistry by Design: Tailoring the Nanoscale Structure of $\mathrm{Pt} / \mathrm{NiO}$ Composites Leads to Enhanced Photoelectrochemical Hydrogen Evolution Performance. J. Phys. Chem. C 2017, 121, 12148-12158.

(8) Halasi, G.; Gazsi, A.; Bánsági, T.; Solymosi, F. Applied Catalysis A : General Catalytic and Photocatalytic Reactions of $\mathrm{H}_{2}+\mathrm{CO}_{2}$ on Supported Au Catalysts. "Applied Catal. A, Gen. 2015, 506, 85-90.

(9) Frontera, P.; Macario, A.; Ferraro, M.; Antonucci, P. Supported Catalysts for $\mathrm{CO}_{2}$ Methanation: A Review. Catalysts 2017, 7 (2), 59.

(10) F. Solymosi, A. E. Hydrogenation of $\mathrm{CO}_{2}$ to $\mathrm{CH}_{4}$ over Alumina-Supported Noble Metals. J. Mol. Catal. A Chem. 1980, No. 8, 471.

(11) Jadhav, S. G.; Vaidya, P. D.; Bhanage, B. M.; Joshi, J. B. Catalytic Carbon Dioxide Hydrogenation to Methanol: A Review of Recent Studies. Chem. Eng. Res. Des. 2014, $92,2557-2567$.

(12) Takashi, I.; Tokio, I. Hydrogenation of Carbon Dioxide and Carbon Monoxide over Supported Platinum Catalysts. J. Chem. Soc. Faraday Transit. 1986, 82, 1681-1686.

(13) An, K.; Alayoglu, S.; Musselwhite, N.; Plamthottam, S.; Melaet, G.; Lindeman, A. E.; Somorjai, G. A. Enhanced CO Oxidation Rates at the Interface of Mesoporous Oxides and Pt Nanoparticles. J. Am. Chem. Soc. 2013, 135 (44), 16689-16696.

(14) Patil, U. V.; Ramgir, N. S.; Karmakar, N.; Bhogale, A.; Debnath, A. K.; Aswal, D. K.; Gupta, S. K.; Kothari, D. C. $\mathrm{CO}_{2}$ Hydrogenation Studies on Co and CoPt Bimetallic Nanoparticles under Reaction Conditions Using TEM, XPS and NEXAFS. Nano Lett. 2014, 136 (May), 4792-4796.

(15) Zheng, F.; Alayoglu, S.; Guo, J.; Pushkarev, V.; Li, Y.; Glans, P.; Chen, J.; Somorjai, G. In-Situ X-Ray Absorption Study of Evolution of Oxidation States and Structure of Cobalt in Co and CoPt Bimetallic Nanoparticles (4 Nm) under Reducing $\left(\mathrm{H}_{2}\right)$ and Oxidizing $\left(\mathrm{O}_{2}\right)$ Environments. Nano Lett. 2011, 11, 847-853.

(16) Sapi, A.; Thompson, C.; Wang, H.; Michalak, W. D.; Ralston, W. T.; Alayoglu, S.; Somorjai, G. A. Recovery of Pt Surfaces for Ethylene Hydrogenation-Based Active 
Site Determination. Catal. Letters 2014, 144 (7), 1151-1158.

(17) Alayoglu, S.; Krier, J. M.; Michalak, W. D.; Zhu, Z.; Gross, E.; Somorjai, G. A. In Situ Surface and Reaction Probe Studies with Model Nanoparticle Catalysts. ACS Catal. 2012, 2, 2250-2258.

(18) Khachatur, M.; Manukyan, V.; Avetisyan, A. g.; Shuck, C.; Chatilyan, H. A.; Rouvimov, S.; Kharatyan, S. L.; Mukasyan, A. S. Nickel Oxide Reduction by Hydrogen: Kinetics and Structural Transformations. J. Phys. Chem. C 2015, 119 (28), $16131-16138$.

(19) Erdohelyi, A., Solymosi F., B. T. Infrared Study of the Surface Interaction between $\mathrm{H}_{2}$ and $\mathrm{CO}_{2}$ over Rhodium on Various Supports. J. Chem. Soc. Farad. Trans. 1981, 77, 2645-2657.

(20) M. Tóth, J. Kiss, A. Oszkó, G. Pótári, B. L.; Erdőhelyi, A. Hydrogenation of Carbon Dioxide on $\mathrm{Rh}, \mathrm{Au}$ and $\mathrm{Au}-\mathrm{Rh}$ Bimetallic Clusters Supported on Titanate Nanotubes, Nanowires and TiO2. Top. Catal. 2012, 55, 747-756.

(21) Fisher, I. A.; Bell, A. T. A Comparative Study of $\mathrm{CO}$ and $\mathrm{CO}_{2}$ Hydrogenation over $\mathrm{Rh} / \mathrm{SiO}_{2}$. J. Catal. 1996, 162 (259), 54-65.

(22) Gómez-Pérez, J.; Dobó, D. G.; Juhász, K. L.; Sápi, A.; Haspel, H.; Kukovecz, Á.; Kónya, Z. Photoelectrical Response of Mesoporous Nickel Oxide Decorated with Size Controlled Platinum Nanoparticles under Argon and Oxygen Gas. Catal. Today 2016, $1-7$.

(23) Borodko, Y.; Habas, S. E.; Koebel, M.; Yang, P.; Frei, H.; Somorjai, G. A. Probing the Interaction of Poly(vinylpyrrolidone) with Platinum Nanocrystals by UV - Raman and FTIR. J. Phys. Chem. B 2006, 110, 23052-23059.

(24) Borodko, Y.; Humphrey, S. M.; Tilley, T. D.; Frei, H.; Somorjai, G. A. ChargeTransfer Interaction of Poly(vinylpyrrolidone) with Platinum and Rhodium Nanoparticles. J. Phys. Chem. C 2007, No. 111, 6288-6295.

(25) Luo, I.; Monai, M.; Wang, C.; Lee, J. D.; Duchoň, T.; Dvořák, F.; Matolín, V.; Murray, C. B.; Fornasiero, P.; Gorte, R. J. Unraveling the Surface State and Composition of Highly Selective Nanocrystalline Ni-Cu Alloy Catalysts for Hydrodeoxygenation of HMF. Catal. Sci. Technol. 2017, 8, 1735-1743. 
(26) Shirley, D. A. High-Resolution X-Ray Photoemission Spectrum of the Valence Bands of Gold. Phys. Rev. B 1972, 5, 4709.

(27) Kattela, S.; Yana, B.; Chena, J. G.; Li, P. $\mathrm{CO}_{2}$ Hydrogenation on Pt, $\mathrm{Pt} / \mathrm{SiO}_{2}$ and $\mathrm{Pt} / \mathrm{TiO}_{2}$ : Importance of Synergy between Pt and Oxide Support. J. Catal. 2016, 343, $115-126$.

(28) Delmelle, R.; Duarte, R. B.; Franken, T.; Burnat, D.; Holzer, L.; Borgschulte, A.; Heel, A. Development of Improved Nickel Catalysts for Sorption Enhanced $\mathrm{CO}_{2}$ Methanation. Int. J. Hydrogen Energy 2016, 41 (44), 20185.

(29) Wang, X.; Shi, H.; Szanyi, J. Controlling Selectivities in $\mathrm{CO}_{2}$ Reduction through Mechanistic Understanding. Nat. Commun. 2017, 8 (1), 513.

(30) Anderson, J. R. Structure of Metallic Catalysts; Academic Press, 1975.

(31) Liu, Q.; Joshi, U. A.; Kevin, U.; Regalbuto, J. R. The Control of Pt and Ru Nanoparticle Size on High Surface Area Supports. Phys. Chem. Chem. Phys. 2014, No. $16,26431-26435$.

(32) Goguet, A.; Schweich, D.; Candy, J. Preparation of a Pt/SiO $\mathrm{S}_{2}$ Catalyst II . TemperatureProgrammed Decomposition of the Adsorbed Platinum Tetrammine Hydroxide Complex under Flowing Hydrogen, Oxygen, and Argon. J. Catal. 2003, 220, 280-290.

(33) Nie, L.; Yu, J.; Li, X.; Cheng, B.; Liu, G.; Jaroniec, M. Enhanced Performance of $\mathrm{NaOH}-$ Modified $\mathrm{Pt} / \mathrm{TiO}_{2}$ toward Room Temperature Selective Oxidation of Formaldehyde. Environ. Sci. Technol. 2013, 47, 277-2783.

(34) Shan, W.; Luo, M.; Ying, P.; Shen, W.; Li, C. Reduction Property and Catalytic Activity of $\mathrm{Ce}_{(1-\mathrm{X})} \mathrm{Ni}_{\mathrm{x}} \mathrm{O}_{2}$ Mixed Oxide Catalysts for $\mathrm{CH}_{4}$ Oxidation. Appl. Catal. A Gen. 2003, 246, 1-9.

(35) Roberts, M. W.; Smart, S. T. C. The Defect Structure of Nickel Oxide Surfaces as Revealed by Photoelectron Spectroscopy. J. Chem. Soc. Farad. Trans. 1984, No. 80, 2957-2968.

(36) Grosvenor, A. P.; Biesinger, M. C.; Smart, R. S. C.; Mcintyre, N. S. New Interpretations of XPS Spectra of Nickel Metal and Oxides. Surf. Sci. 2006, 600, 17711779. 
(37) Kucharczyk, B.; Tylus, W.; Okal, J.; Chęcmanowski, J.; Szczygieł, B. The Pt-NiO Catalysts over the Metallic Monolithic Support for Oxidation of Carbon Monoxide and Hexane. Chem. Eng. J. 2016, 309, 288-297.

(38) Antill, J. E., Wartburton, E. J. Oxidation of Nickel by Carbon Dioxide. J. Electrochem. Soc. 1967, 114, 1215-1221.

(39) Kelemen, S. R. The Reaction of Carbon and Water as Catalyzed by a Nickel Surface. Appl. Surf. Sci. 1987, 28 (4), 439-474.

(40) Commerce, U.S.S. of. NIST X-ray Photoelectron Spectroscopy Database https://www.srdata.nist.gov/xps/.

(41) Wiltner, A.; Linsmeier, C. Formation of Endothermic Carbides on Iron and Nickel. Phys. Status Solidi Appl. Res. 2004, 201 (5), 881-887.

(42) Steinbach, F.; Kiss, J.; Krall, R. Identification and Stability of $\mathrm{CH}_{3}, \mathrm{CH}_{2}$ and $\mathrm{CH}$ Species on Co and Ni Surfaces, A PES Investigation. Surf. Sci. 1985, 157, 401-412.

(43) Calderón, S. K.; Grabau, M.; Óvári, L.; Kress, B.; Steinrück, H. P.; Papp, C. CO Oxidation on Pt(111) at near Ambient Pressures. J. Chem. Phys. 2016, 144, 044706.

(44) Lesiak, B.; Stobinski, L.; Malolepszy, A.; Mazurkiewicz, M.; Kövér, L.; Tóth, J. Journal of Electron Spectroscopy and Preparation of Graphene Oxide and Characterisation Using Electron Spectroscopy. J. Electron Spectros. Relat. Phenomena 2014, 193, 92-99.

(45) Commerce, U. S. S. of. NIST X-ray Photoelectron Spectroscopy Database.

(46) Vayssilov, G. N.; Lykhach, Y.; Migani, A.; Staudt, T.; Petrova, G. P.; Tsud, N.; Skála, T.; Bruix, A.; Illas, F.; Prince, K. C.; et al. Support Nanostructure Boosts Oxygen Transfer to Catalytically Active Platinum Nanoparticles. Nat. Commun. 2011, 10, 310 315.

(47) Henry, C. R.; Luminy, C. De; Cedex, M. Surface Studies of Supported Model Catalysts. Surf. Sci. Rep. 1998, 31, 231-325.

(48) Raskó, J. CO-Induced Surface Structural Changes of Pt on Oxide-Supported Pt Catalysts Studied by DRIFTS. J. Catal. 2003, 217, 478-486.

(49) S. Ishi, Y. Ohno, B. V. An Overview on the Electronic and Vibrational Properties Of 
Adsorbed CO. Surf. Sci. 1985, 161, 349-372.

(50) Bennett, C., Ueno, A; Hochmuth, J. K. Interaction of $\mathrm{CO}_{2}, \mathrm{CO}$, and $\mathrm{NiO}$ Studied by Infrared Spectroscopy. J. Catal. 1977, 235, 225-235.

(51) Baltrusaitis, J.; Schuttlefield, J.; Zeitler, E.; Grassian, V. H. Carbon Dioxide Adsorption on Oxide Nanoparticle Surfaces. Chem. Eng. J. 2011, 170 (2-3), 471-481.

(52) Ferencz, Z.; Erdo, A.; Baan, K.; Oszko, A.; Óvári, L.; Kónya, Z.; Papp, C.; Steinrück, H.-P.; Kiss, J. Effects of Support and Rh Additive on Co-Based Catalysts in the Ethanol Steam Reforming Reaction. ACS Catal. 2014, 4, 1205-1218.

(53) Henderson, M. A.; Worley, S. D. An Infrared Study of the Hydrogenatlon of Carbon Dioxide on Supported Rhodium Catalysts. J. Phys. Chem. 1985, 20 (1982), 1417-1423.

(54) Solymosi, F.; Knözinger, H. Infrared Spectroscopic Study of the Adsorption and Reactions of $\mathrm{CO}_{2}$ on K-Modified $\mathrm{Rh} / \mathrm{SiO}_{2}$. J. Catal. 2015, 177 (1990), 166-177.

(55) Truong, C. M.; Wu, M.; Goodman, D. W. Adsorption of Formaldehyde on Nickel Oxide Studied by Thermal Programmed Desorption and High-Resolution Electron Energy Loss Spectroscopy. J. Am. Chem. Soc. 1993, 67 (13), 3647-3653.

(56) Raskó, J.; Kecskés, T.; Kiss, J. Formaldehyde Formation in the Interaction of HCOOH with Pt Supported on $\mathrm{TiO}_{2}$. J. Catal. 2004, 224, 261-268.

(57) Raskó, J.; Kecskés, T.; Kiss, J. Adsorption and Reaction of Formaldehyde on $\mathrm{TiO}_{2}-$ Supported Rh Catalysts Studied by FTIR and Mass Spectrometry. J. Catal. 2004, 226, $183-191$.

(58) Kecskés, T.; Raskó, J.; Kiss, J. FTIR and Mass Spectrometric Studies on the Interaction of Formaldehyde with $\mathrm{TiO}_{2}$ Supported Pt and Au Catalysts. Appl. Catal. A Gen. 2004, 273, 55-62.

(59) Chuang, C.; Wu, W.; Huang, M.; Huang, I.; Lin, J. FTIR Study of Adsorption and Reactions of Methyl Formate on Powdered $\mathrm{TiO}_{2}$. J. Catal. 1999, 434, 423-434.

(60) Liao, L.; Wu, W.; Chen, C.; Lin, J. Photooxidation of Formic Acid vs Formate and Ethanol vs Ethoxy on $\mathrm{TiO}_{2}$ and Effect of Adsorbed Water on the Rates of Formate and Formic Acid Photooxidation. J. Phys. Chem. B 2001, 105, 7678-7685.

(61) Chang, Z.; Thornton, G. Effect of Pd on the Interaction of Formic Acid with $\mathrm{TiO}_{2}(110)$. 
Surf. Sci. 2000, 459, 303-309.

(62) Brieger, C.; Melke, J.; Kaghazchi, P.; Roth, C. CO Adsorption on Platinum Nanoparticles - the Importance of Size Distribution Studied with In-Situ DRIFTS and DFT Calculations C. Brieger. ECS Trans. 2015, 69 (17), 249-253.

(63) Solymosi, F.; Erdőhelyi, A.; Kocsis, M. Surface Interaction between $\mathrm{H}_{2}$ and $\mathrm{CO}$ on $\mathrm{Rh} / \mathrm{Al}_{2} \mathrm{O}_{3}$, Studied Adsorption and Infrared Spectroscopic Measurements. J. Catal. 1980, 436, 428-436.

(64) Freund, H.; Robert, M. W. Surface Chemistry of Carbon Dioxide. Surf. Sci. Rep. 1996, $25,225-273$.

(65) Ishi, S. I.; Ohno, Y.; Viswanathan, B. An Overview on the Electronic and Vibration Properties of CO. Surf. Sci. 1985, 161, 349-372.

(66) Bell, T.; Shustorovich, E. Analysis of CO Hydrogenation Pathways Using the BondOrder- Conservation MEthod. J. Catal. 1988, 113, 341-352.

(67) Williams, K. J.; Boffa, A. B.; Salmeron, M.; T., B. A.; Somorjai, G. A. The Kinetics of $\mathrm{CO}_{2}$ Hydrogenation on Rh Foil Promoted by Titania Overlayers. Catal. Letters 1991, 9 , 415-426.

(68) Brown, L. R.; Hunt, R. H.; Pine, A. S. Wavenumbers, Line Strengths, and Assignments in the Doppler-Limited Spectrum of Formaldehyde from 2700 to 3000 $\mathrm{Cm}^{-1}$. J. Mol. Spectrosc. 1979, 75, 406-428.

(69) Wang, X.; Shi, H.; Kwak, J. H.; Szanyi, J. Mechanism of $\mathrm{CO}_{2}$ Hydrogenation on $\mathrm{Pd} / \mathrm{Al}_{2} \mathrm{O}_{3}$ Catalysts : Kinetics and Transient DRIFTS-MS Studies. ACS Catal. 2015, 5, 6337-6349. 
TOC Graphics

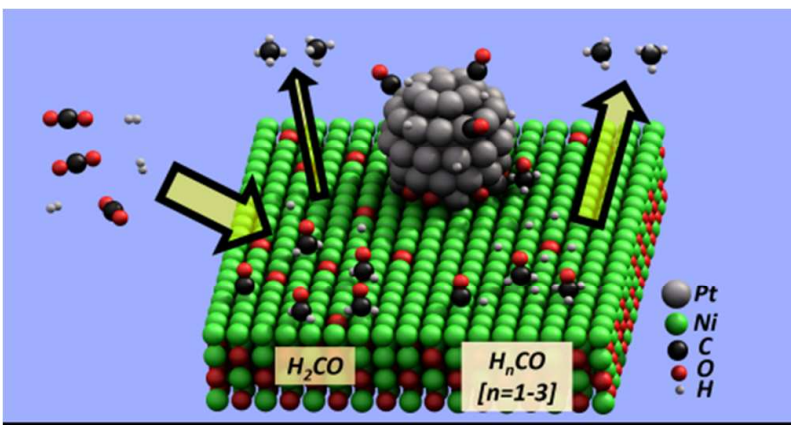




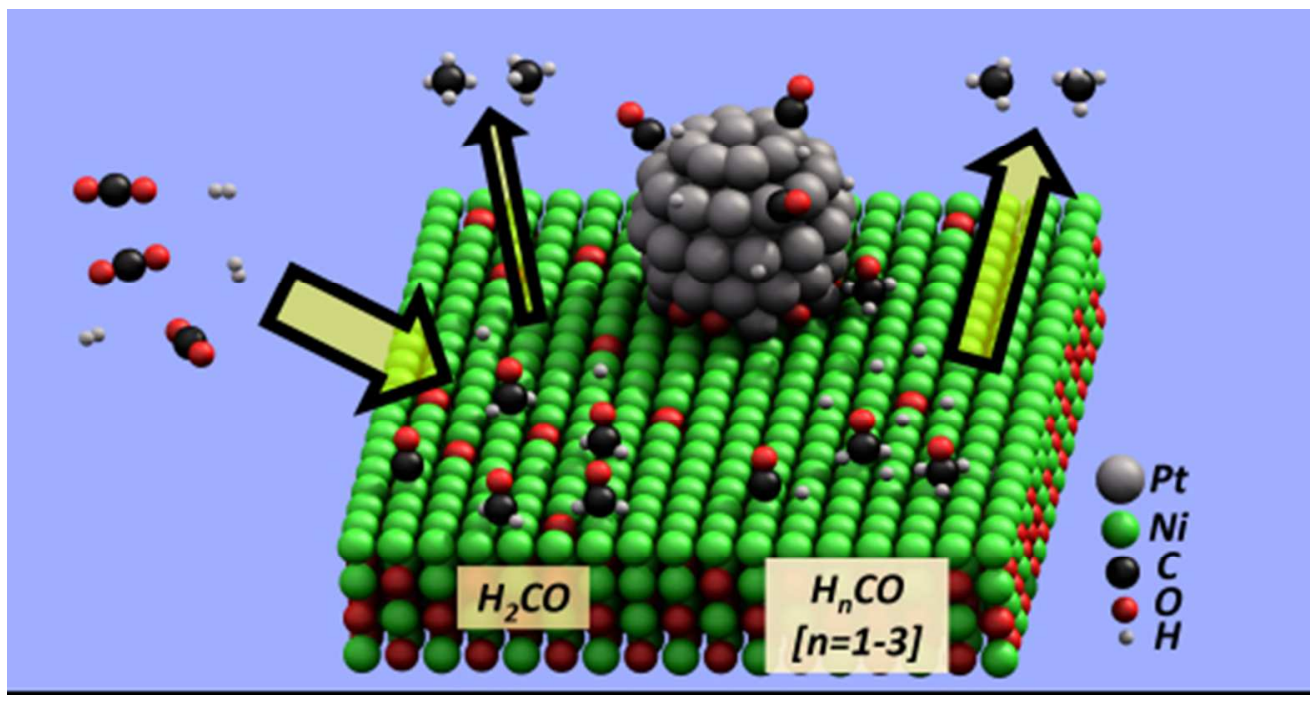

TOC Graphic

$85 \times 44 \mathrm{~mm}(150 \times 150 \mathrm{DPI})$ 